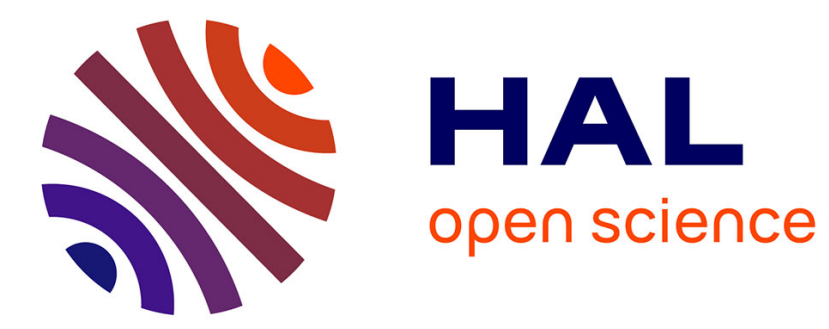

\title{
Nouvelles épaves de Provence (III)
}

Fernand Benoit

\section{To cite this version:}

Fernand Benoit. Nouvelles épaves de Provence (III). Gallia - Fouilles et monuments archéologiques en France métropolitaine, 1962, 20 (1), pp.147-176. 10.3406/galia.1962.2352 . hal-01931204

\section{HAL Id: hal-01931204 https://hal.science/hal-01931204}

Submitted on 25 Feb 2020

HAL is a multi-disciplinary open access archive for the deposit and dissemination of scientific research documents, whether they are published or not. The documents may come from teaching and research institutions in France or abroad, or from public or private research centers.
L'archive ouverte pluridisciplinaire HAL, est destinée au dépôt et à la diffusion de documents scientifiques de niveau recherche, publiés ou non, émanant des établissements d'enseignement et de recherche français ou étrangers, des laboratoires publics ou privés.

\section{(이) $\$$}

Distributed under a Creative Commons Attribution - NonCommercial - NoDerivatives| 4.0 


\title{
NOUVELLES ÉPAVES IDE PROVENCE (III ${ }^{1}$
}

\author{
par Fernand BExorT
}

Le contrôle des recherches faites sur le littoral par les plongeurs bénévoles a apporté des documents de grand intérêt pour l'histoire de l'économie antique el celle des relations commerciales, en particulier des ports de Marseille ot de Fos à l'époque romaine : ceux-ci permettent de renouveler la typologie des amphores de Iressel. de reconnaître leur provenance et parfois la nature de leur contenu et de dresser la Forma maris antiqui, qui n'aurait pu être faite sans leur concours et dont la richesse s'accroît tous les ans. Mais ce starle de la prospection individuelle, qui relève du sport et de la curiosité d'amateurs. s'il a permis de localiser une quarantaine d'épaves sur notre còte, et de sauver des pièces isolées et des fragments d'amphores dispersées dans les "cimetières marins " (qui n'apparaissent que temporairement sous l'action de courants), n'est pas sans danger pour l'étude scientifique des "gisements". Les prélèvements, trop souvent clandestins, sur la couche superficielle des gisements, qui se présentent comme de véritables tumulus signalés par des débris d'amphores, peuvent détruire le contexte des divers éléments de l'épave. A ce stade préliminaire de la découverte, qui bénéficie de la législation de Colbert sur le "sauvetage des biens perdus en mer "2, doit succéder la phase "archéologique" de la fouille sous-marine: olle ne pourra être faite qu'à l'aide de moỵens lechniques et financiers qu'il est urgent de donner à cette nouvelle section de l'archéologie, si l'on veut préserver ce patrimoine historique d'une disparition totale.

\section{BOLCHES-Dl-RHÒNE}

1. Fos (Fossae Marianae). -- Les recherches méthodiques du groupe de recherches sous-marines d'Istres ( $D^{r}$ Beaucaire ${ }^{3}$ dans le golfe de Fos, ont amené la découverte de pièces de grand intérêt pour l'armement et gréement naval et pour l'histoire du commerce :

(1) Voir Gallia, XIV-1956, p. 23-24; XV1-1958, p. 5-39; XVIII-1960, p. 41-56.

(2) La loi sur les fpaves maritimes du 24 novembre 1961 et le décret dapplication du 26 décembre 1961 (.J.O. des 25 nov. 1961 et 12 janvier 1962 j se bornent à adapter l'ordonnance de 1681 à la législation actuelle. 1 , inventeur de l'epave doit en faire la déclaration à l'Inscription . Varitime dans les 48 heures ; lorsque l'épave constitue un gisement archéologique, il est procédé à la récupération de l'épave soit par l'État, soit par un concessionnaire, acerédité par le Ministre des Affaires Culturelles, sous la surveillance du Directeur régional des Antiquitis. I. Oinventeur de l'ópave a droit à une indemnité et la rémunération donnée au concessionnaire de la récupération peut ètre attribuée en nature ; mais la détérioration d’une épave ayant un interèt archeologique est passible de sanctions très séveres ;art. 257 du code pénal.

3 Giallia, NVI-195is, p. 34-37. 


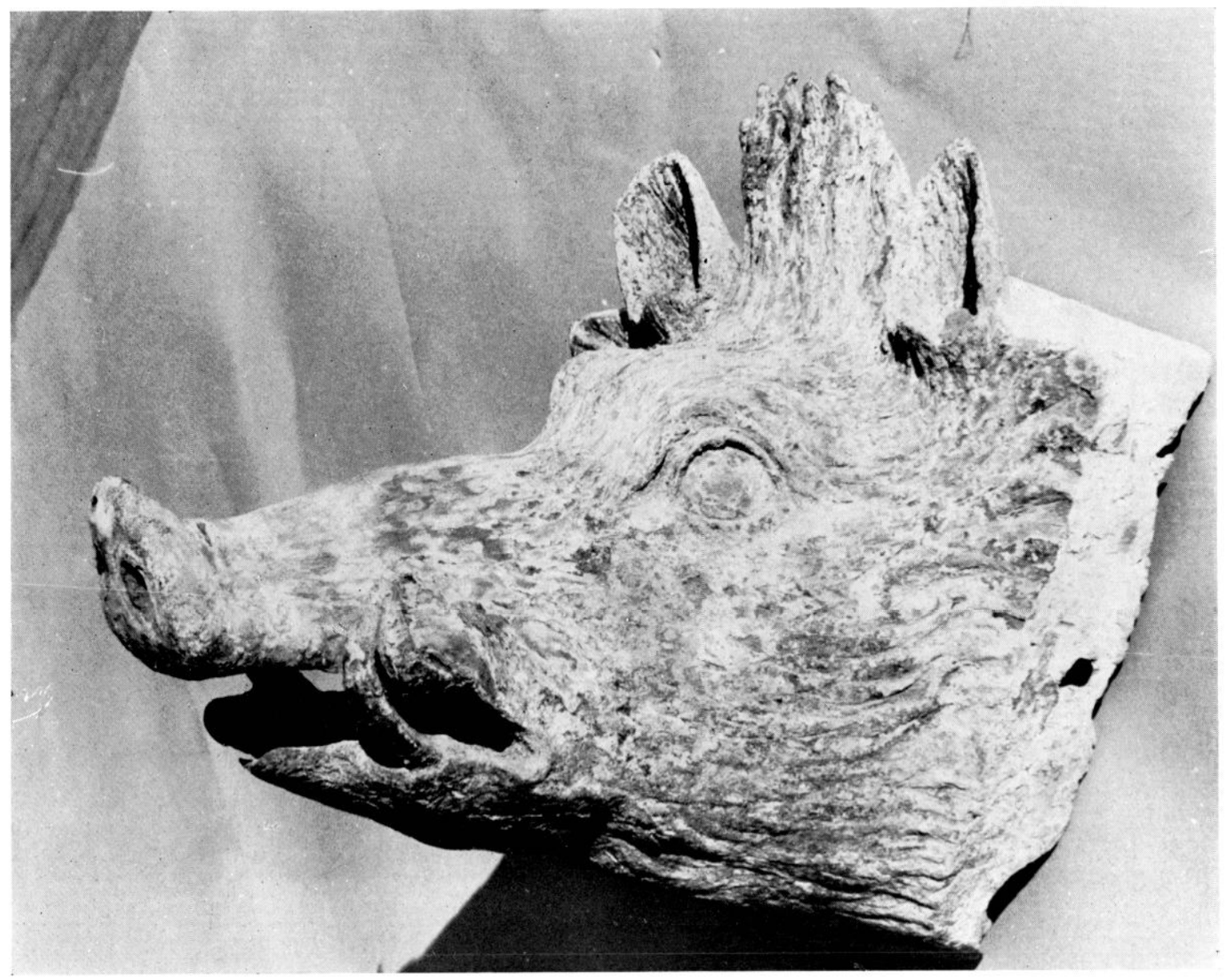

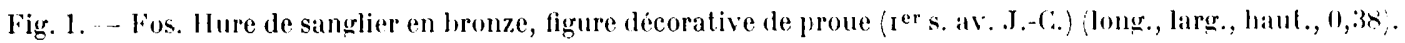
Musíe d'Istres. Cl. Dr Beauctiore.

a) dans la haie, à 1 lilomètre du littoral, à 40 mètres de l'épave déja signaléce à - 12 mètres hure de sanglier en bronze (fig. 1) remontée avec un petit vase à deux anses (haut. $0 \mathrm{~m} .20$ ), du poids de 13 kilos : la tète d'applique attenant à un chapeau de bronze, qui a conservé un clou, était sans doute une figure décorative de proue. destinée à coiffer l'extrémité de la préceinte. La tête d'époque hellénistique (II-I er s. av. J.-(i.) est analogue. a celles de lion et de loup de l'épave de Nemi ${ }^{4}$, de l'époque de Cialigula;

b) sur le littoral de l'anse Saint-Gervais, aflouille par la mer, amphores de types divers: massaliète ovoïde (haut. $0 \mathrm{~m}$. 53) ; hispaniques de tradition punique (lypes . Yaña (:, I) ot. E) ${ }^{5}$; romaines à saumure de Bétique (Pelichet 46 a 48 ) ; sphériques de Bétique (1)ressel 20 B), avec marques sur l'anse $S \Lambda$ E $N$ I A N ES (es). P. S. A V (iti) e et graflites I I. V A (ni); ovoüdes rempliess d'arêtes de poisson (fig. :?) (Dressel 10) ; cylindriques a goulot

(4) G. LCELLI, Le navi di Nemi, 1950, fig. 230-237.

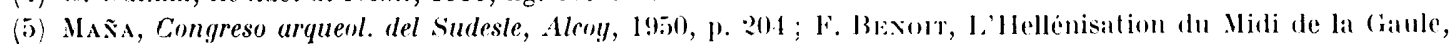
$1^{\text {re }}$ partie (a paraitre).

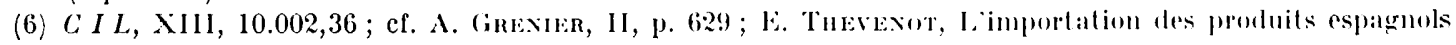
chez les Éduens et les Lingons, Rev. arch. Est, 1, 1950, p. 70 et 71, 11. 3. 


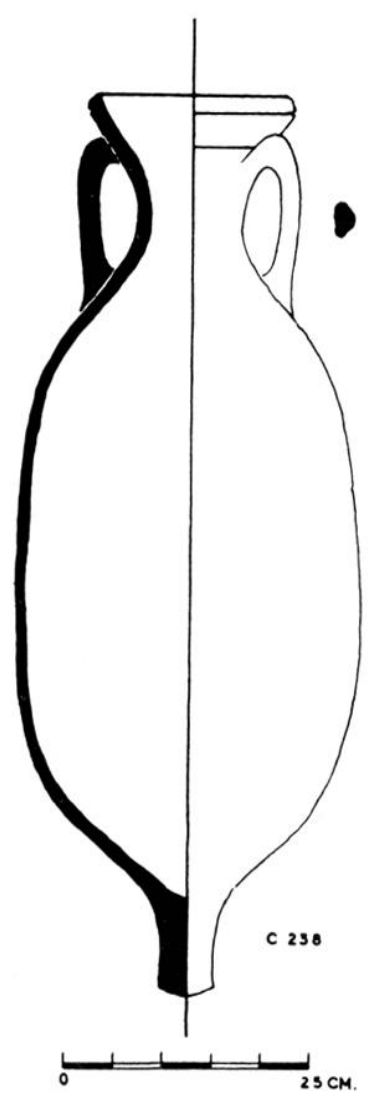

Fig. 2. Fos. Amphore à saumure contenant des arêtes de poisson. $1 \mathrm{~m} .10$. Musée d'Istres.

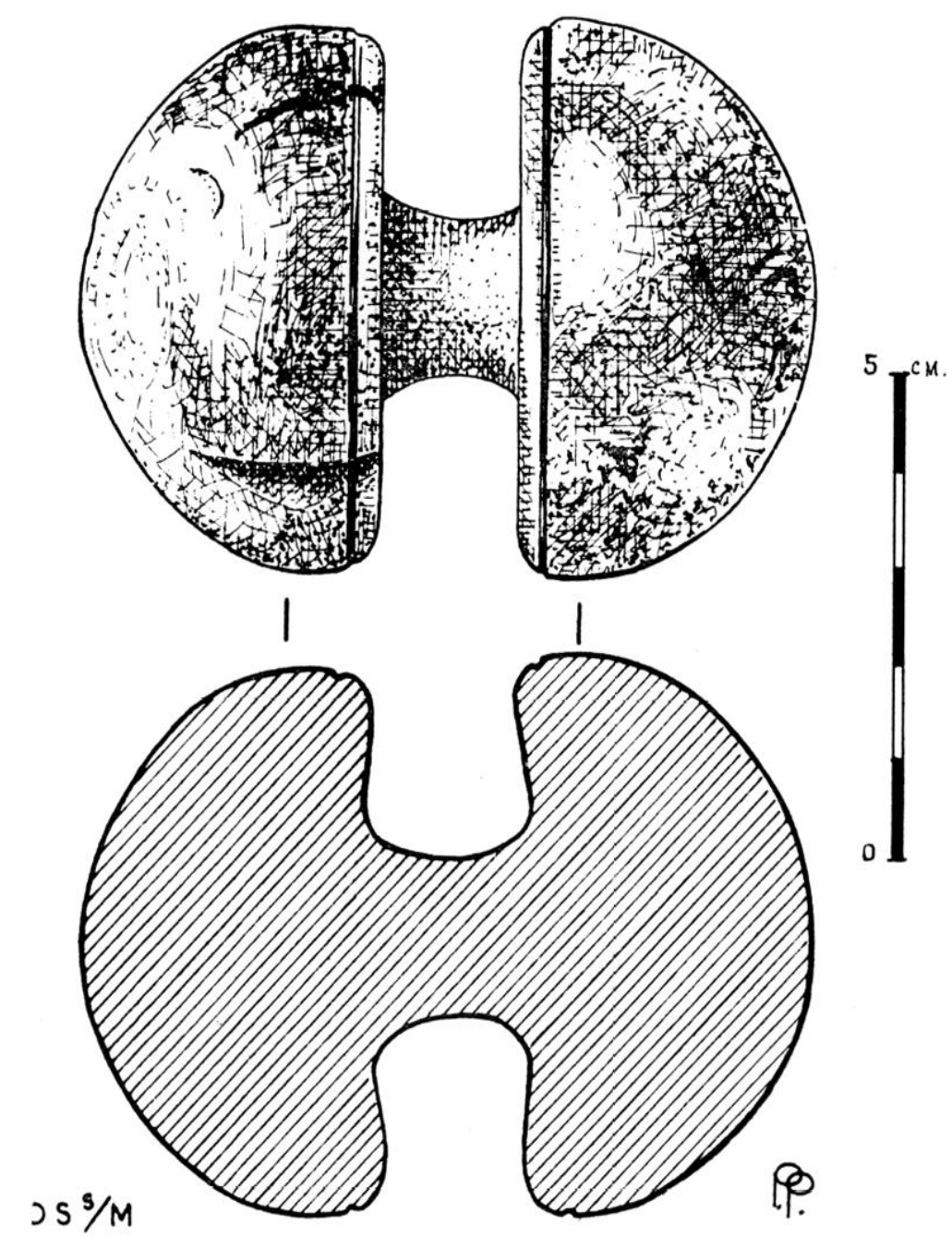

Figr. 3. Fos. bepotoir. Bohine de marine a enrouler le fil. Bois. Musie d'Istres.

étroit du Bas Empire (I)ressel $26 / 27$, Almagro $: 2:$ ) ; piriformes à cannelure ct goulot court érasé, du Bas Empire (Dressel 31/32) ${ }^{\boldsymbol{7}}$;

c) dans la couche d'allurions argileuse, sous-jacente au sable de l'anse Saint-Grervais, a -2 ' mètres, provenant d'un dépotoir' : pièces de gréement (poulie, bobine (fig. 3), ustensiles de ménage en bois (pyxides (fig. 4), peignes, brosses en chiendent. cages, chevalets de lyre a huit cordes et plectre (fig. is et 6), cuir) : agate à deux couleurs du III ${ }^{\mathrm{e}}$ s. représentant la déesse Rome (fig. 7); céramique campanienne à vernis noir du $\mathrm{I}^{\mathrm{er}}$ s.; Arezzo (marque SEX.II (urrius) FE (cit) ; Lezoux (marque II OXSI YS) ${ }^{8}$; tuiles (marques A PRI, H E R (ennius) O (plalus), et une série remarquable de cols et panses d'amphores avec inscriptions peintes, capitales et cursives, en grec et en latin, la plupart des premiers siècles

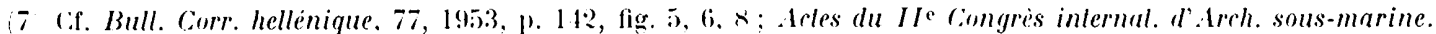
Albenga 1961, p. 243 , fig. 2:).

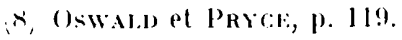




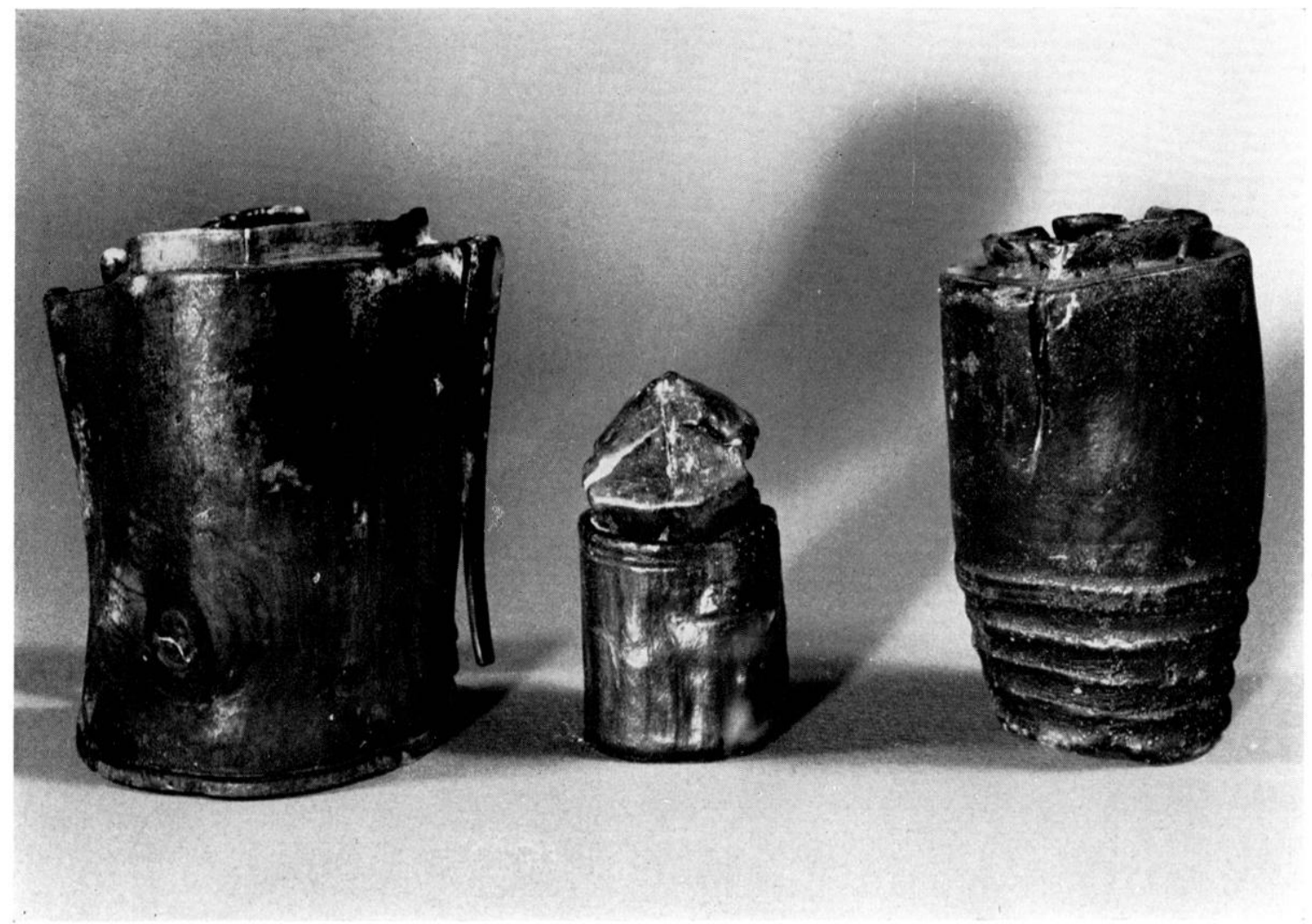

Fig. 1. Fos. Depoloir. Pyxides de hois. Musce de Istres.

avant et apress J.-t..., d'un grand intérèt pour connaitre les itinéraires commerciaux de Fos avec Rhodes (Phoebeum rinum). la grande (iriece et l'Esparne, la nat ure des produits. garum. sel, vin de Rhodes et d'Aurelia (Carisa regia) en Bétique, vin poissé (picalum velus) et poissé à l'écoree (corlixarium), et le formulaire commercial (musée d'Istres) 9 .

d) On a depuis longtemps signalé à peu de distance du port de Fos en mer des tas de pierres (5 a 10 kilomètres) parsemés de débris d'amphores, plus ou moins alignés parallèlement au littoral ${ }^{10}$. Ie cap. Monguilan a remarqué la mème disposition à l'entrée du petit port de Stora à l'O. de Philipperille en Algérie : il suppose que les navires se déchargeaient. du lest et du matériel vide arant d'areoster à la plage d'embarquement. Il a noté que less rols d'amphores recomaissables appartenaient dans les deux sites au Bas Limpire.

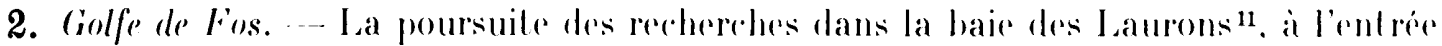
du petit port de Sénèmes. aujourd'hui alterri, que dégagent les fouilles de .l. A. Lottiti2, a amené la découverte d'un type noureau d'amphore ; sur un fond de sable dégagé par les rourants, a 100 metres du rivage of - - 12 metres : amphore sphérigur romplete (haut

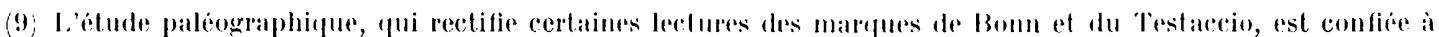
mon confrien cih. Perrat.

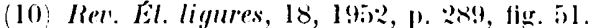

(11) Gallia, X1111-1960, p. 13, 3 (1 wpe I)ressel 3/1).

(12. Ibid., XII-1954, p. 433, figr. 15 et 16 ; et XX-196?. 


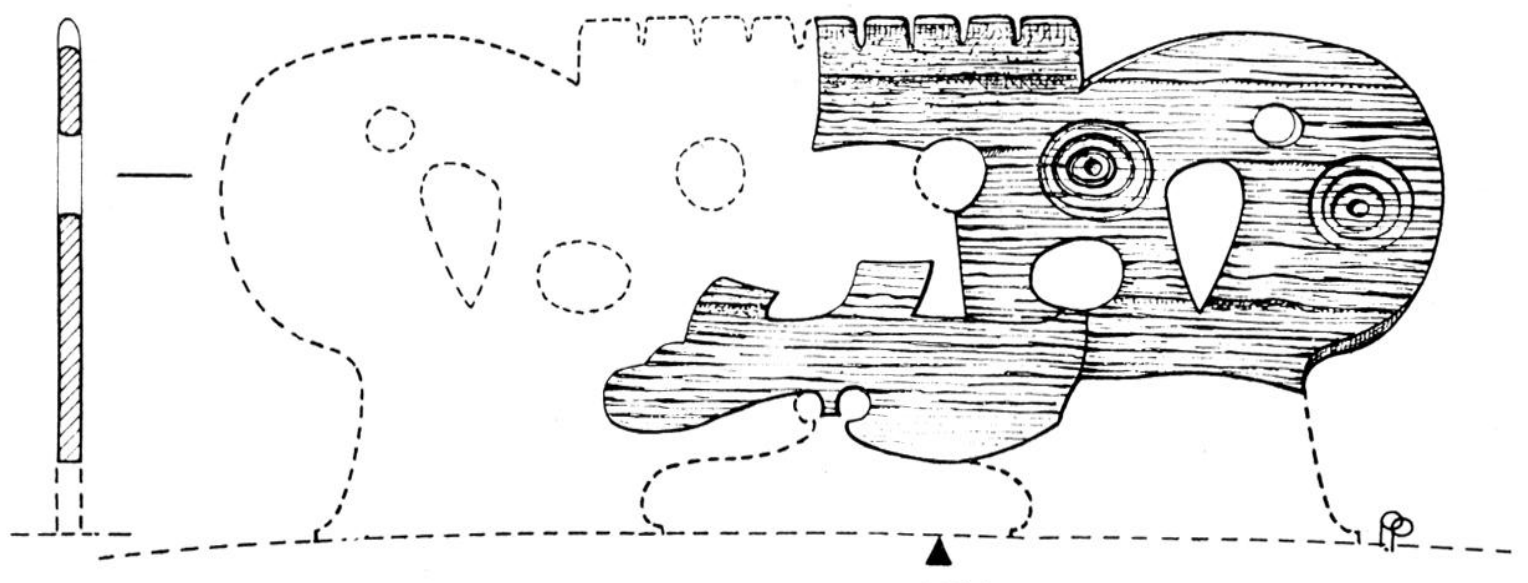

$\mathrm{FOS} \% \mathrm{M}$

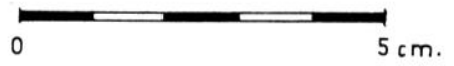

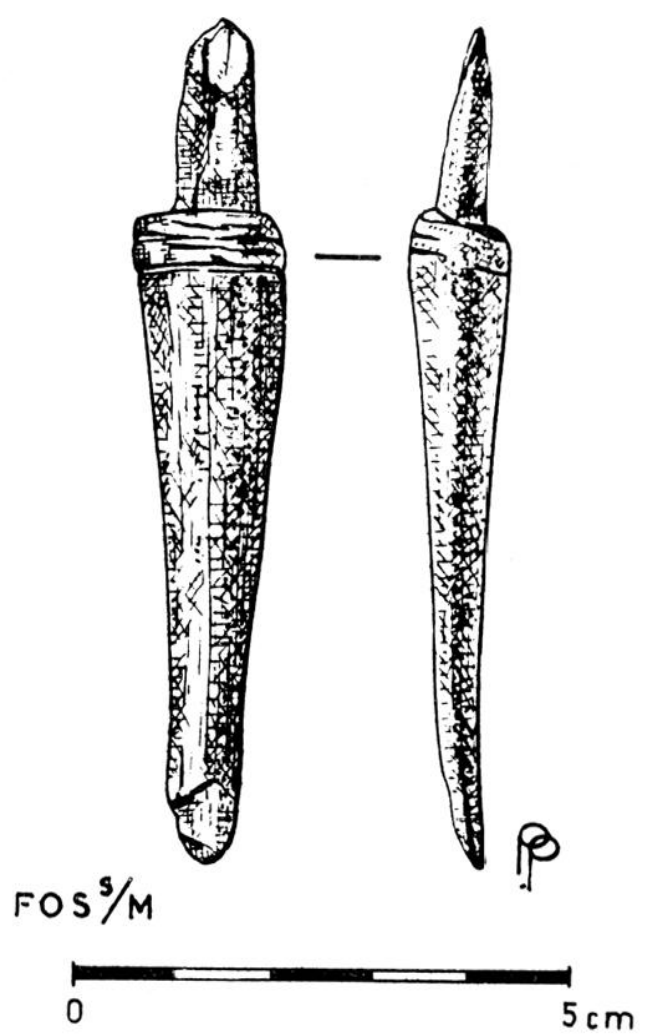

Fig. 5-6. Fos. Dépoloir. Chevalet de lyre a $x^{2}$ cordes

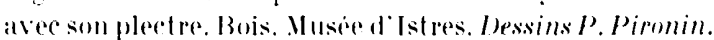

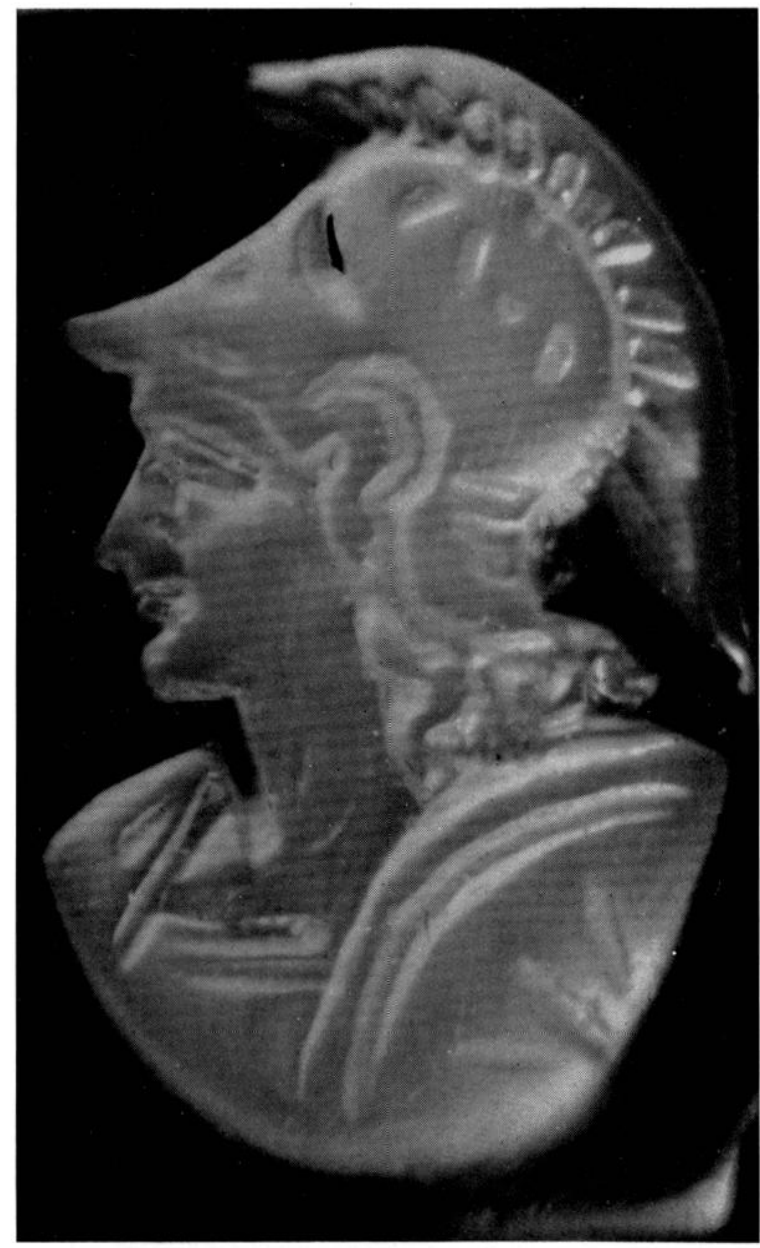

Figr. 7. Fos. Dépotoir. Camée avec profil de la déesse Rome $0,01 \times \times 0,01: 3$. 


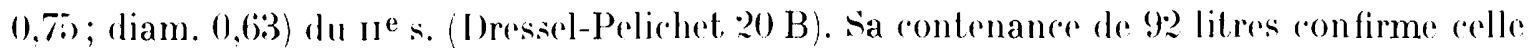
qui avait ete domée par une amphore de mème type trouvé a Ithiza, portant le nom de Scimnius, dont la figlina était à Astigi en Bétique ${ }^{13}$. Le coté d'une anse corrodée porte une marque rectangulaire sur deux lignes $0.0(?)$.../. $\mathrm{Ml}$ \& R..., qui se retrouve sur une ligne dans un exemplaire d'Agde. A signaler également un anneau de grand diametre en pierre (0,39) in. 1. Esmenjaud, (.. 3333 at 334).
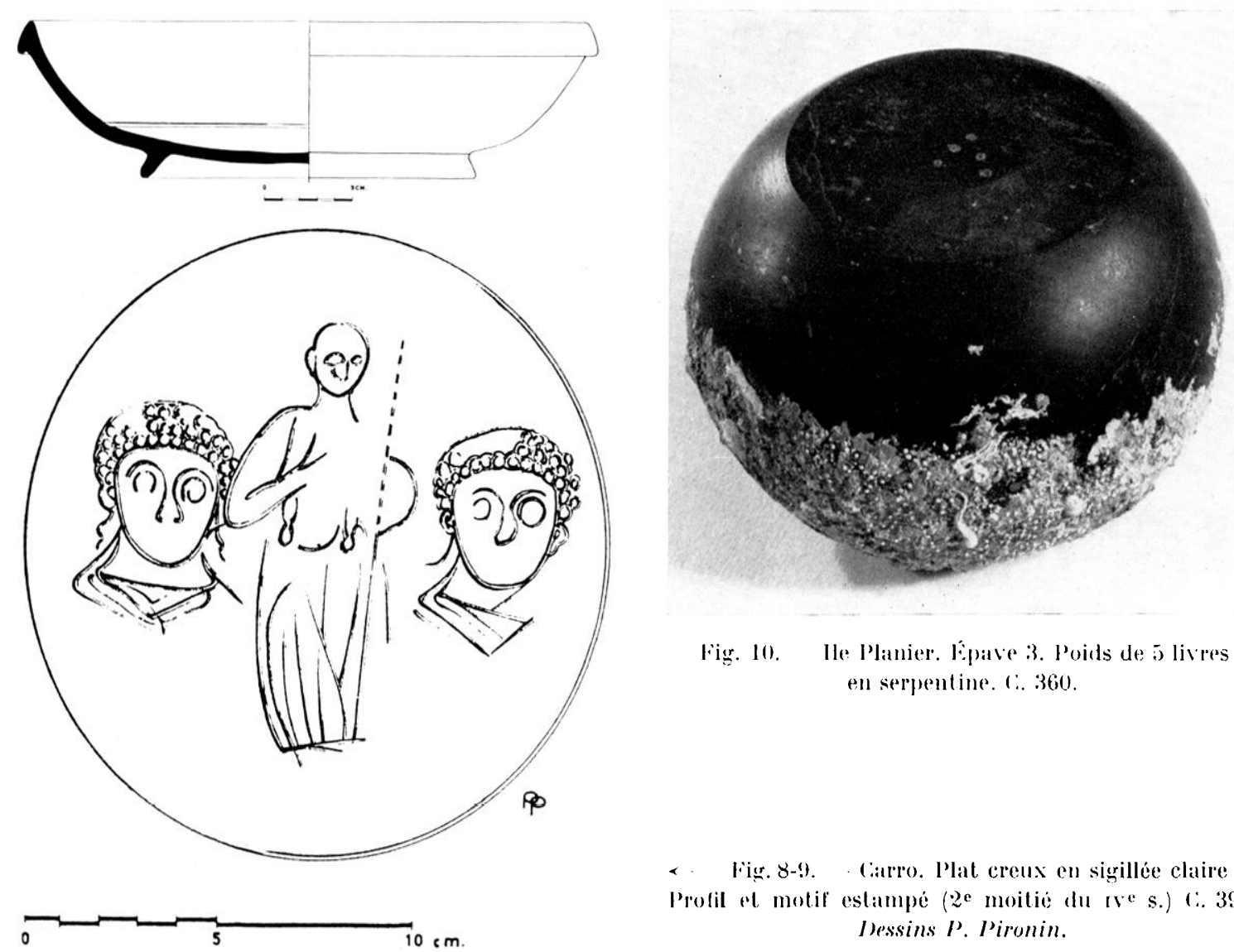

Fig. 10. He Planier. Fipave 3. Poids de j lives enserpentine. 1.360 .

\section{Bair de Marssills}

3. Carro. - A 300 mètres du littoral, a -5 metres, dans un "cimetière marin " d'amphores, harre de plomb, jas d'ancre ou lingot, (long. 0,80 ; section $0,07 / 8$; poids 36 lilos) et plat creux en sigillée (laire l), portant une gravure estampée (2) moitié du ree s.) (fig. 8 ct 9) : personmage cuirassé tenant unc haste cntre deux bustes virils, peut-ètre les l)ioscures, dont le style se rapproche du plat aux ldioscures encadrant la roix, des fouilles de Marseille 14 (Ciap Monguilan (.. 39)? al 391).

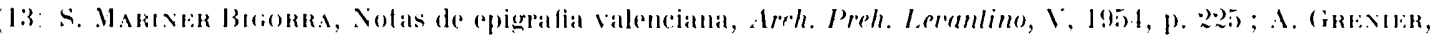

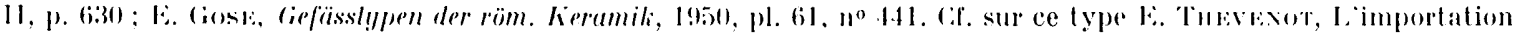
des produits expagnols che\% les liduens, l. r., p. 66 .

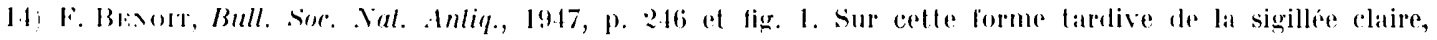

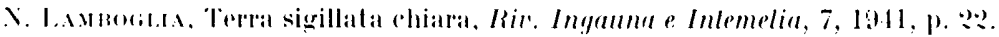


4. Niolon. -- A la calanque de la Corbière, à ?0 mètrés du littoral, à -8 mètres, dalle trapézoïdale de pierre perée de trois trous. l'un rond en haut pour le passage d'une corde, les deux autres carrés en bas pour la fixation de madriers ou de crochets (.1. R. Martin (. 340). d'usage et d'époque indèterminés ${ }^{15}$ : "engin " pour la pèche du corail 16 ou plut òt lest d'ancere a crochels de bois.

\section{Marseille}

5. Planier 2. - Le chargement d'amphores sphériques du ${ }_{11}{ }^{\mathrm{e}}$ s. venant de Bétique ${ }^{17}$ ust confirmé par la découverte d'autres exemplaires intacts du type Dressel-Pelichet $20 \mathrm{~B}$
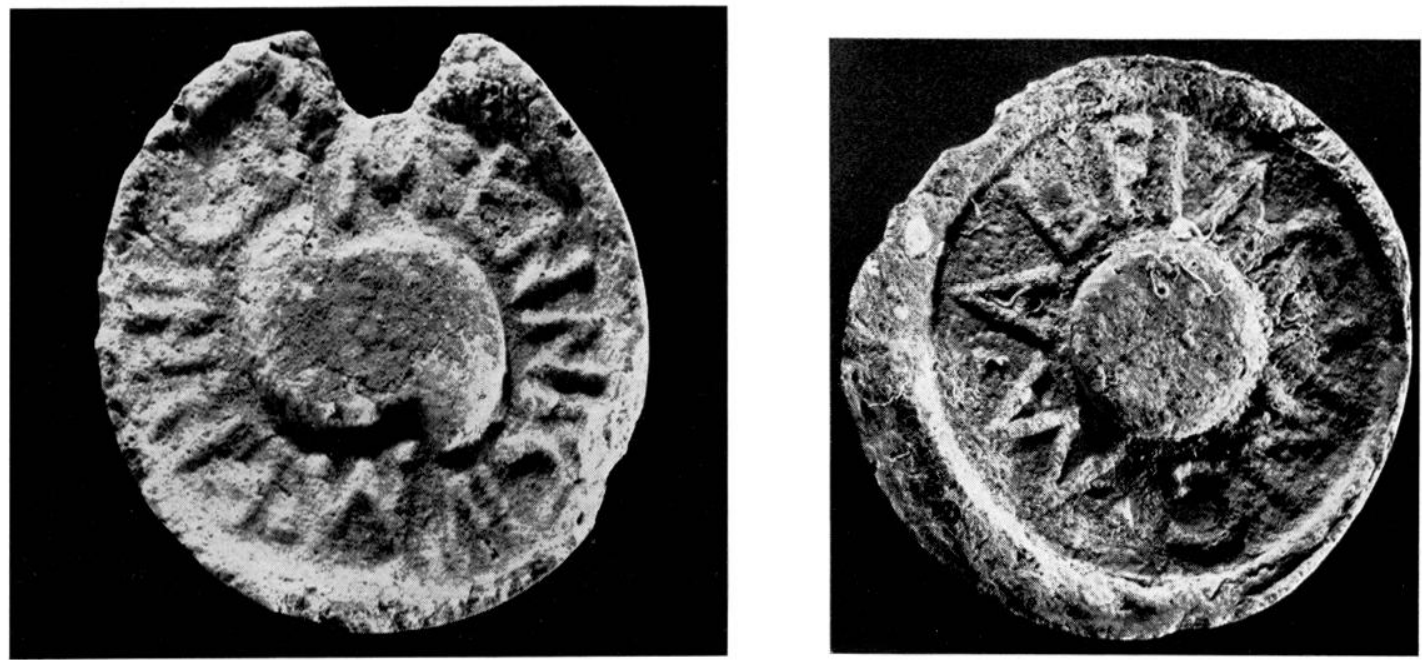

Fig. 11-12. . Ile Planier. Epave 3. Bouchons d'amphores aux noms d'Ennius el d'Alfius, parfumeur (diam. 0,095 et 0.10) (: 343. C.\% Bristle.

(O F R S et (. 43:2 sans marque) ; - gros anneau de pierre avec tenon peré de deux trous (diam. 0,40 ; larg. 0,08; ép. 0,05) (0 F R S. (. . 422).

6. Planier 3. - A 250 mètres S.-0. de l'île, à -3:) mètres, au pied du tombant du récif de la Pierre de la Bogue, épave d'amphores italiques (Dressel 1 B); série de gobelets ovoïdes en poterie commune (C. 361); poids de serpentine en forme de sphère tranchéc (fig. 10) portant une marque $\mathrm{V}$ [livres] faite de cinq clous de cuirre fet autres de $\mathrm{X}$. 11 et $S(e m i s):(\therefore .360)^{18}$; houchons de chaux (fig. 11 et 1:) dans cols d'amphores italiquess (Dressel IB) :

II. E N N I. (: I ... (C. 343, 344) ${ }^{19}$

(15) Plusieurs dalles de ce type, de 0,45 env, de haut. ont eté trouveses sur la cote anx environs de .larseille . Niolon (:. 340 ; Planier (. 400 ; Frioul 6731 ; "plateau des Cheves ", ile de Jare 8499 : ces deux dernieres, Rel". El: ligures, 21,1955, p. 126 et fig. 9 .

(16) Infra, 18.

(17) Callia, XIV-1956, p. 27, 2 et fig. 2,24.

(18) Cf. poids analogue en néphrite bleue, de plus petite dimension idiam. 0,052 ; ép. 0,035; poids de 158 gr. 25) portant le chiffre $X X$, ponctur par des globules (provenant sans doute de J.uc-en-I)iois, musée de Gap L. 2.125.

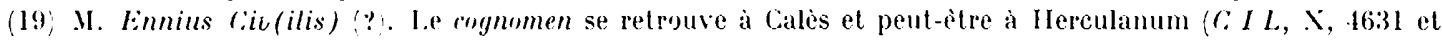

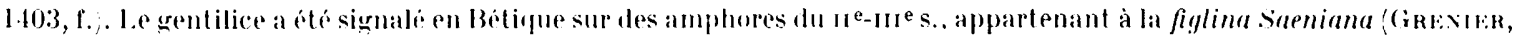
II, p. 629 . 
et II. A I. F I. V F. V N G (uenlarius) (matrice ronde d'une seule pièce sans répétition du nom) (( $6.342,345)$, au nom d'un parfumeur originaire sans doute de Capoue ${ }^{20}$, dont la nombreuse épigraphie montre le parti industriel que cette ville avait tiré de ses champs de roses sauvages; - manche de patère en bronze à tête de panthère (fig. 13 et 14), d'une technique de fabrication particulière; la tête en bronze fondu adaplé à un manche cannelé également en bronze fondu. recouvert d'une feuille de cuivre rouge repoussé argentée en surface (.I. J. Bouis, laboratoire du musée Borély : ( .403$)$ (M. J. Gelindo).
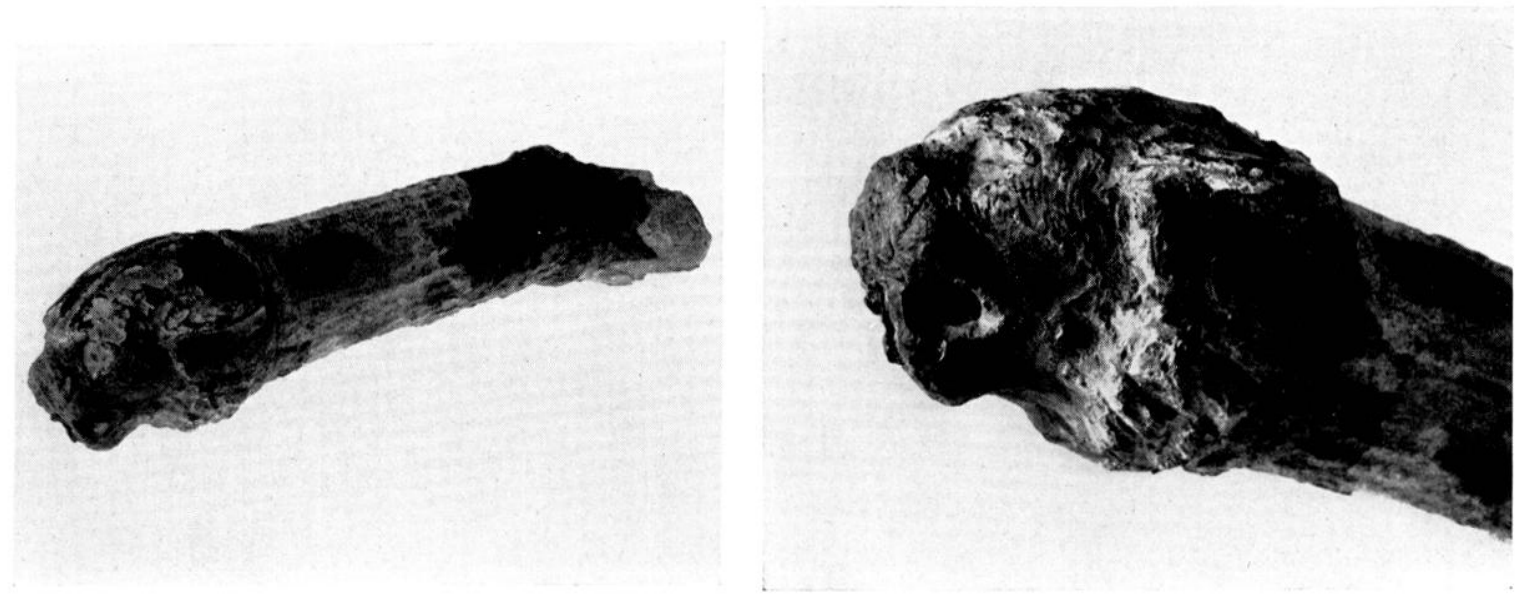

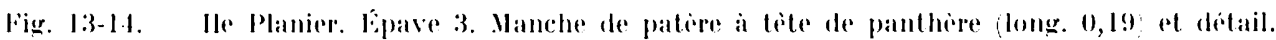
Bronze. 1., 10:3. (.\%. Briolle.

7. Planier 4. - Au bas du tombant du Souquet, a 40 mètres 0. de l'épave :2, -2:2/ 25) mètres, gisement (pillé). qui semble diflérent de celui-ci, également en provenance de Bétique : amphores a panse piriforme cel gros pied, à col évasé en forme de corolle el anses longues (C. 4:6) (fig. 15) ${ }^{21}$; autre de mème type, mais à col plus large (diam. 0,23) terminé par une courte lère droite (haut. sans le pied, 0,94: (..367) (fig. 17), avec marque ... () (:, du Iers.; -- lingots de cuive en forme de flans circulaircs (diam. 0,45; ép. 0,13;0.30 et $0.04)$ ( fig. 18 et 19), le petit pesant i0 k. 500), le gros 95) k. 500); celui-ci porte une inscription incisée après la fonte:

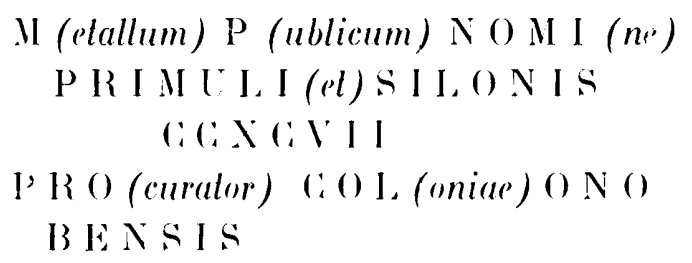

Lettres irrégulieres (haut 0,02) à 0,04). Ligature $11 \mathrm{P}$ à la première ligne avee dépassement de la première haste de 11 (rendant possible la lecture I M P (eratoris) N () .I I (ne);

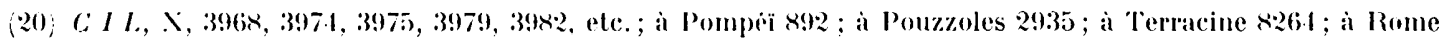

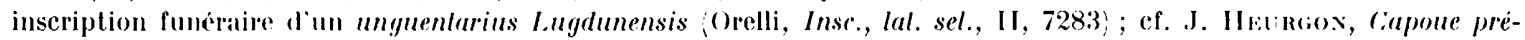
romaine, p. 15.

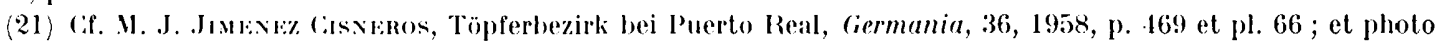
Le Moult : ici (fig. 16) ; ipave d Anthéor II : Gallia, NIV-1956, p. 30, 12 et fig. 2, $1^{\text {os }} 19-20$. 

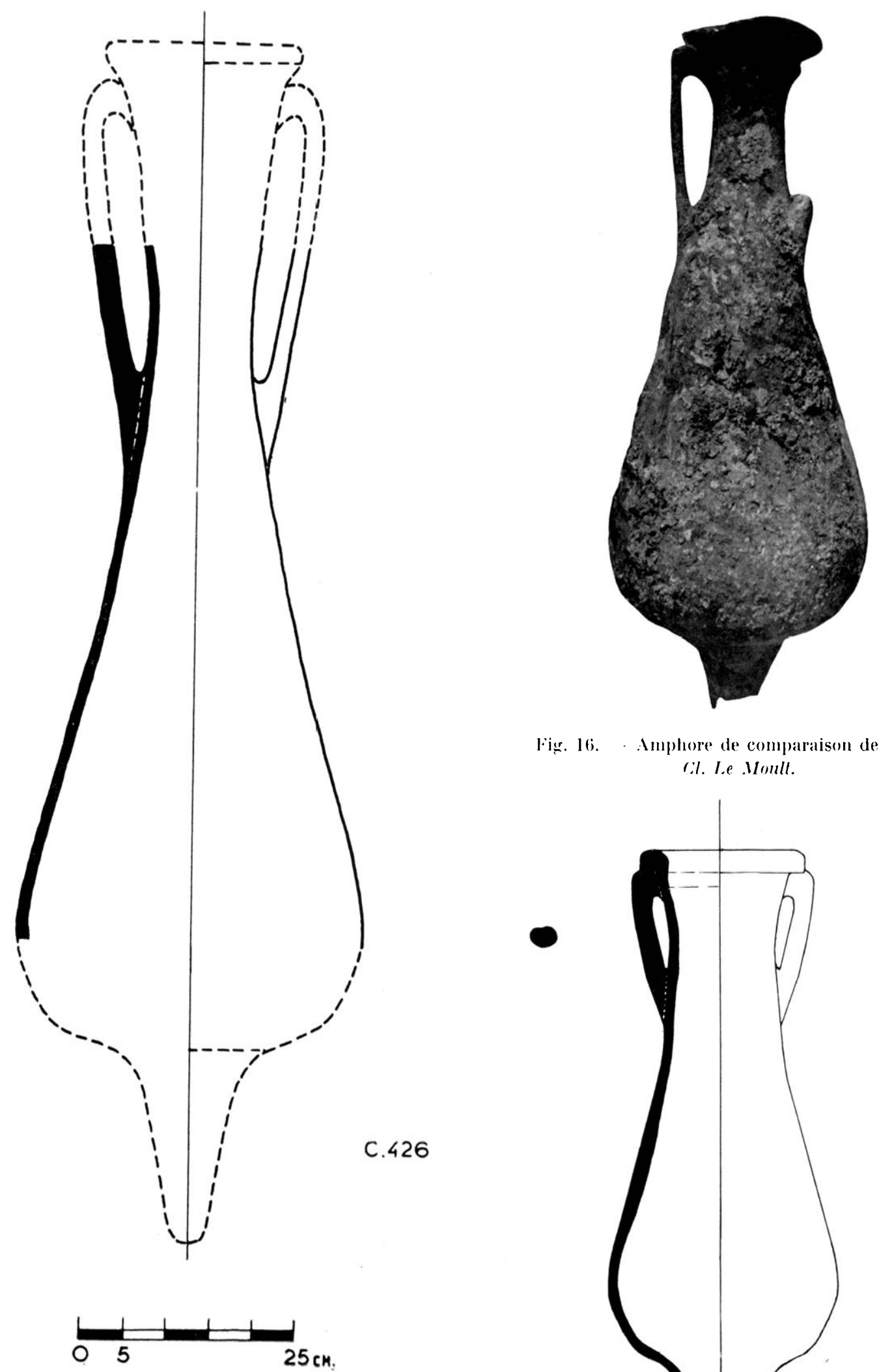

Fïr. 16. Amphore de comparaison de Cadlix. C. I.e . Yoult.

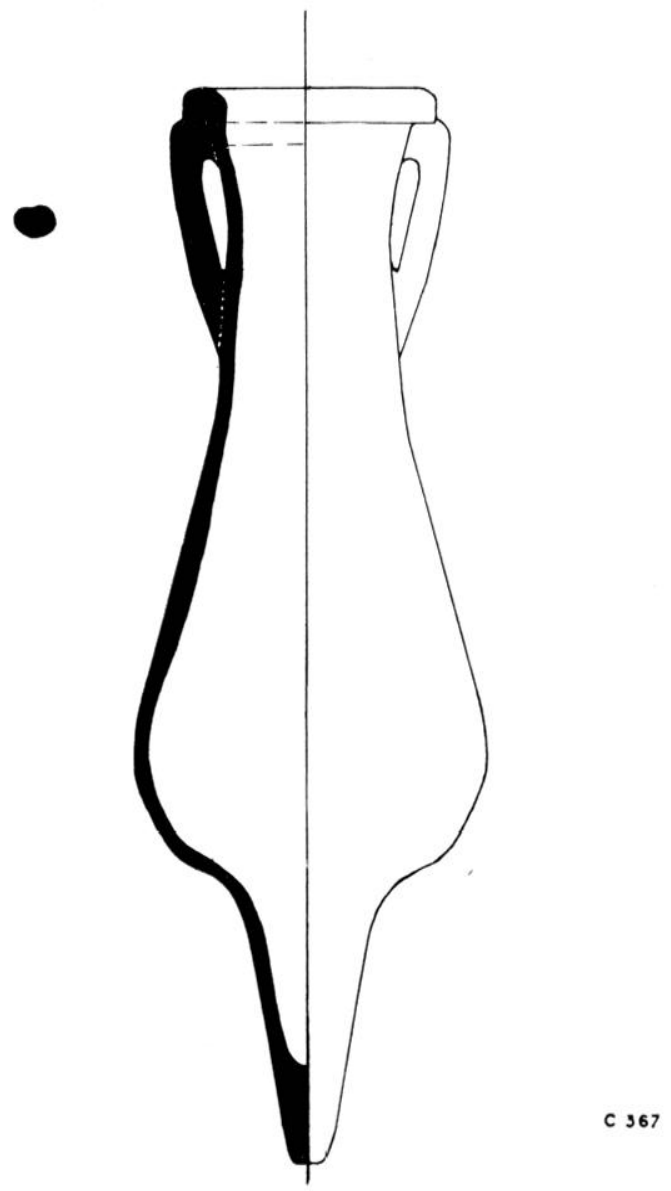

Jïg. 17. Lle Planier. lipave 4. Amphore du lipe ... d'Augst (pied reconstitué. Iessin .M. Borely.

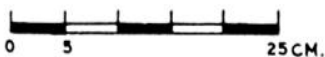


() plus petil ; barre horizontale de I. prenant son atlache au-dessus de la ligne et incliné au-dessous romme dans l'ériture africaine (MI). J. Cielindo. M. Pouderigne : (2. 370. 411 $11 \cdot 2)$.

La provenance du lingot en "ruivere cordouan" d'(Onuba, auj. Hurlva, dans la Sirrra Morena (le Mons Marianus de Pline ${ }^{22}$, a un grand intérèt pour l'histoire éronomique of

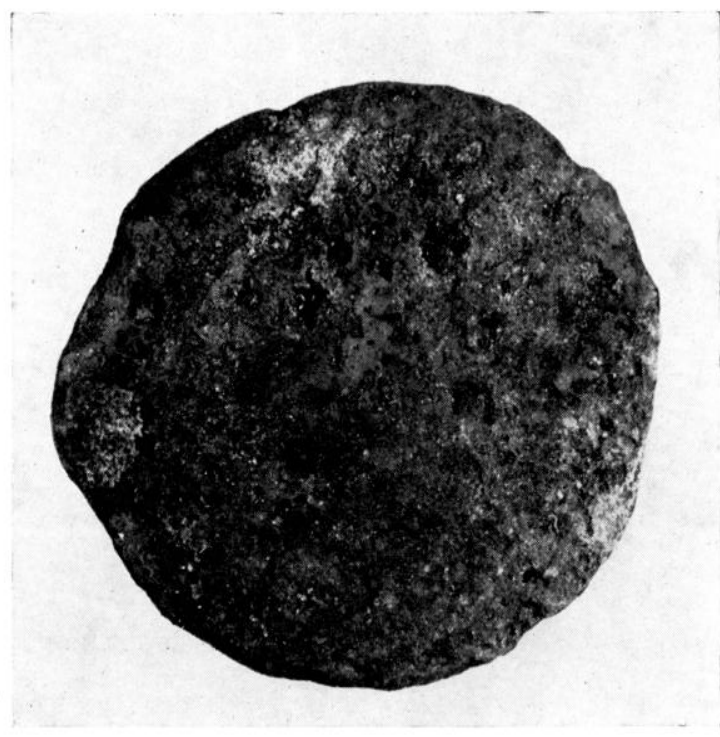

Jïg. 18. He Planier. Épave 4. Jingot de enive sans marque, poids $10 \mathrm{~kg}$. 500 . C. . 111 et $11 \%$. l'ardministration des mines sous l'Lmpireziz. Cel oppidum ét ait un centre mét allurgique tris important dies l'age du Bronze, en relation avere les mines du Rio Tinto at Mispalis, at un port d'exportation qualifié par Pline d'itsharia".

L'inseription est complite. la rugosite de la partie droite du lingot ayant empèché de graver sur toute la surface du disque. Elle porte la mention des conductores de la mine, Primulus et Silo, dont le nom est connu en Espayne. le poids 997 livres, soit 97 kilos. rorrespondant au poids actuel aprese unc legrere perte de matiòre, at le contròle du procuraler ${ }^{25}$, representant le fisce, imposé aux fermiers de la collectivité des colons ou "xploitants at dont la contremarque devail être gravée sur la tranche ${ }^{26 .}$

8. Planier io. A 150 mètres (). de l'ile, a ....35/40 mètres sur fond de sable, épave d'amphores italiques, de différents types, la plupart hrisées : amphores à col court à panse plus ou moins ovoüde (Dressel 10) (fig. 20 at 21). dont deux exemplaires centiers contenaient des coquilles d' amandes de mer" ou grosses clovisses an conserve (pitaria chione. lutraria "l surtout pectunculus pilosus), coquilles abondantes con Méditerranée à l'époque antique (11. J. Gelindo 393. 402) ; fragments de cols de type analogue. à livere évasée ((i. 40\%)-407); 2 jas d'ancre en plomb à boìte rectangulaire au milieu du gisement de $1 \mathrm{~m}$. 45 et $1 \mathrm{~m}$. 25 long (c. 394, 397) ; pattes d'une ancre en fer avere incrustation de coquille de peclunculus pilosus (c. 404).

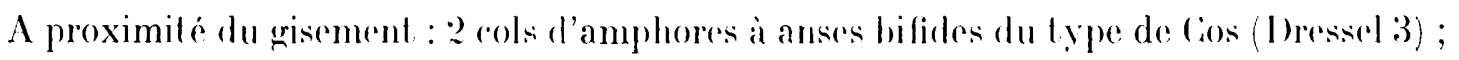
plomb de sonde hémisphérique a deux trous pour l'anneau de suspension (traces de fere

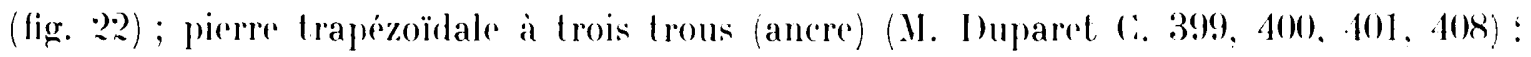
gros anneau de pierre brisé sans tenon (diam. 0,39) (396).

9. Planier 6. - Aus.-(). de l'île, à l’o., de la Pierre de la Bogue el au sud de l'épave 3 ,

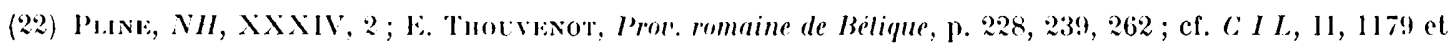
$5181 ; R E$, s.r. Onuba; et infra $33,1$.

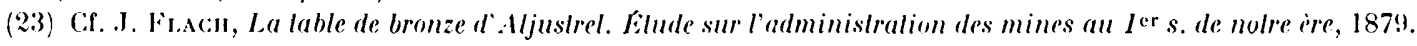

(2.) 13. Tuolvinot, o.c., p. 194, n. 1.

(25) C.f. la mention du proc. Monlis Mariani (CLL, II, 1179).

(26) Cf. infra 33, 4 ; lingot de cuivre d'Agde (comm. de M. Bouscaras:. 


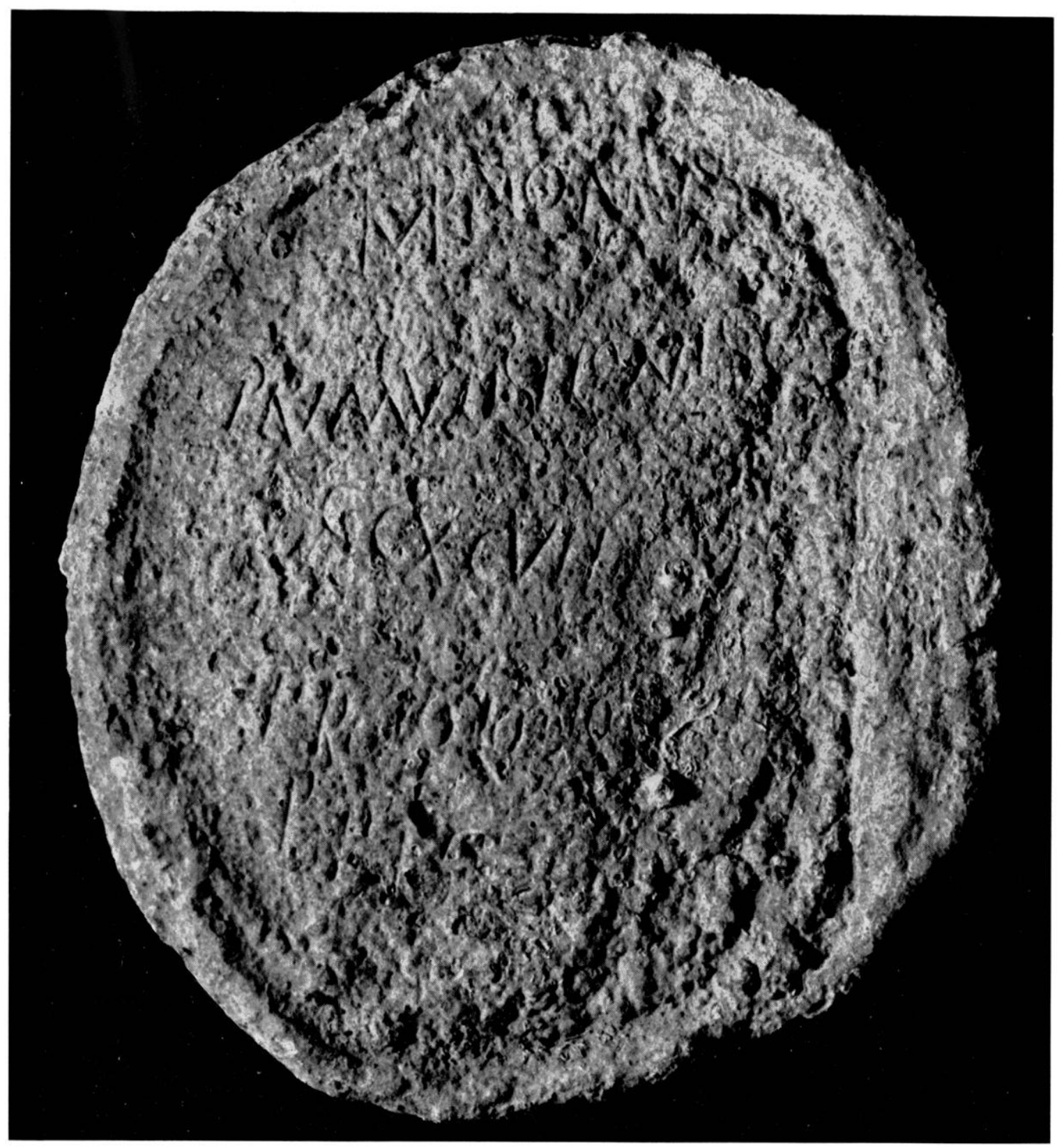

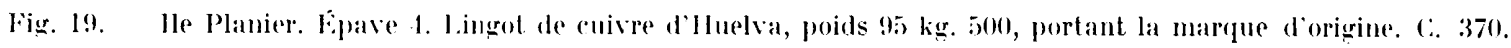
(.) Briolle.

a 35 metres, gisement reconnaissable à de nombreux débris d'amphores italiques (II. J. Gelindo).

10. Planier 7. A 45 mètres de la pointe X.-0.. de l'île, à - $18 / 50$ melres sur fond de sable, epare occupant un espare de $7 \times 8$ metres (fig. 233 ), dont une partie du chargement a glissé sur la pente vers le $\mathrm{X}$.. a - bi) metres. Le contexte des amphores révele une pro-

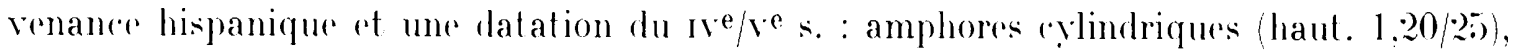
a goulot plus ou moins étroit. terminé par un simple bourrelet, col court et petiles anses. 


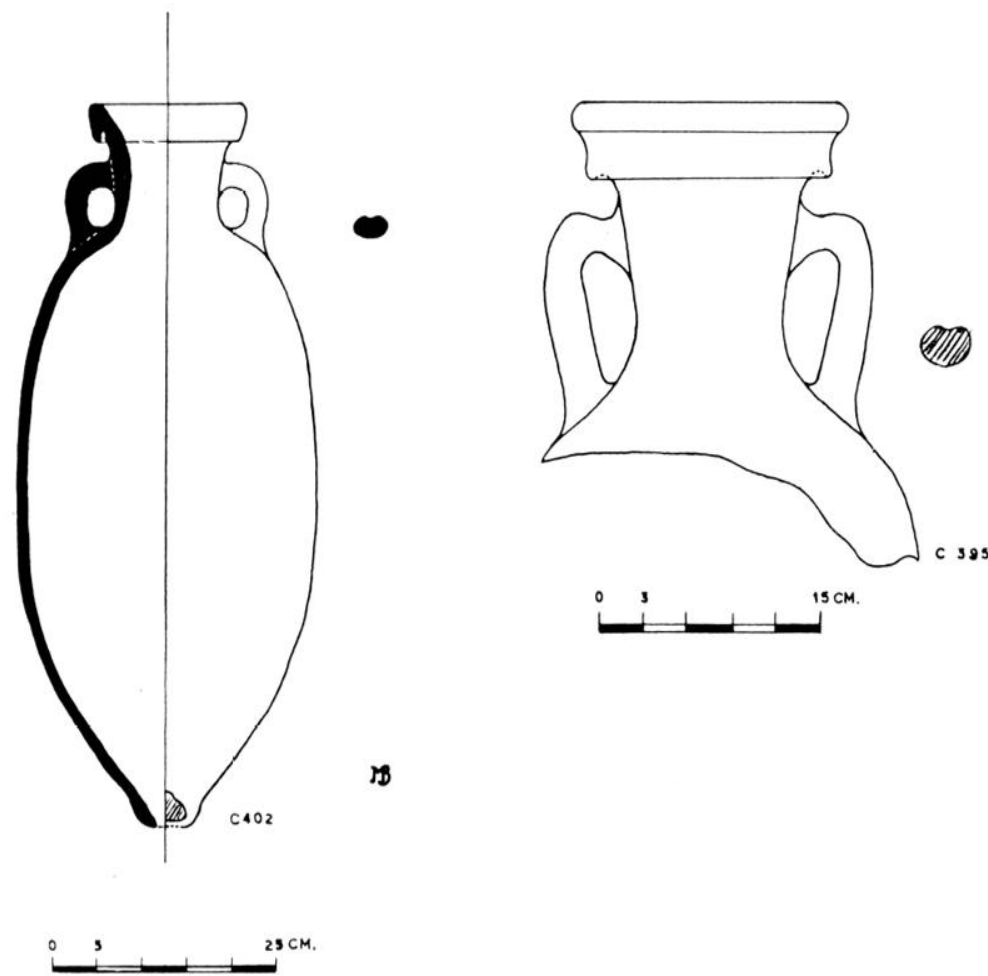

lïg. 20. He Planier. Fipare 5. Amphores ovoüdes a conserve de poisson.

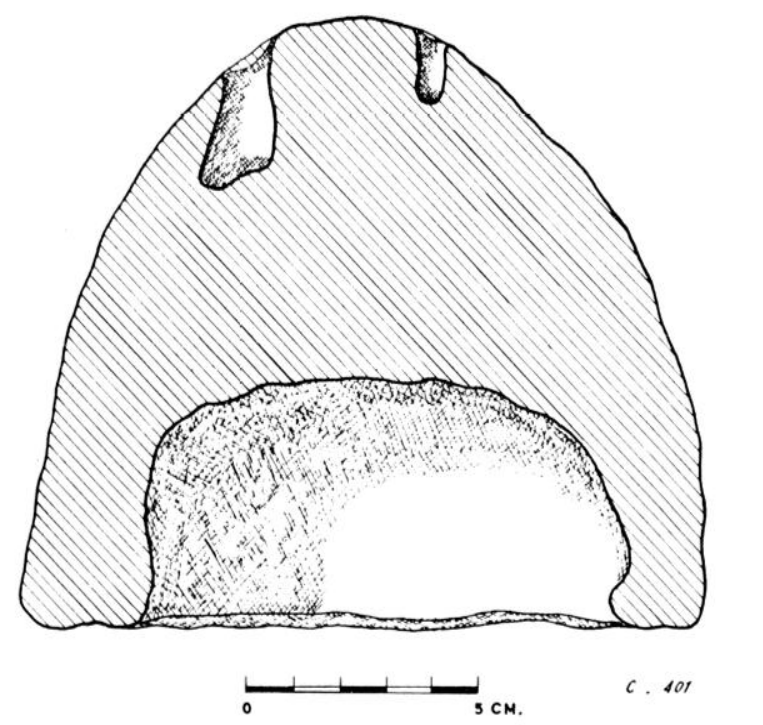

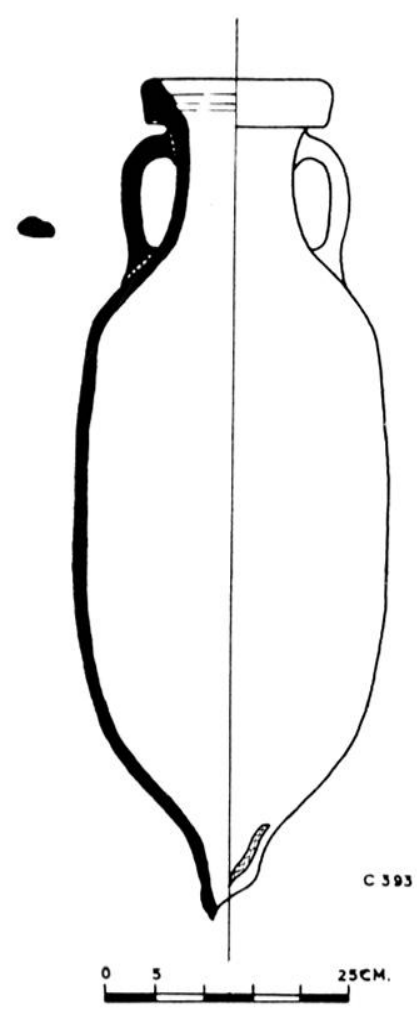

Fig. 21. He Planier. Ljave: Amphore ovoide a conserve do poisson. Dessins .M. Boreily.

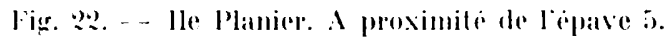
Plomb de sonde (diam. inf. 0, 15). C. 101. 


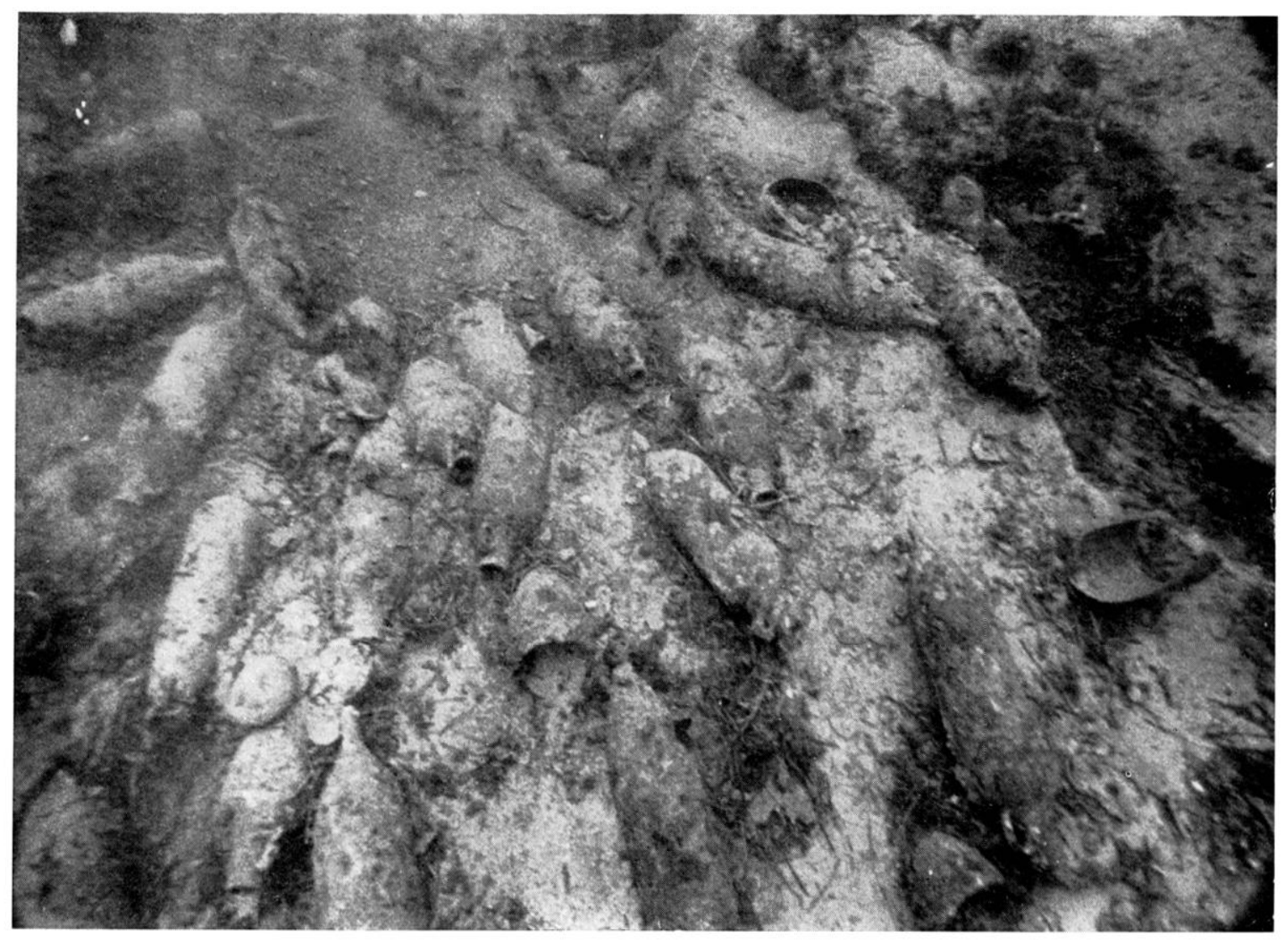

Fig. 2:3. - Ile Planier. lipave 7. I.e gisement alant le pillage. Cl. OFRS.

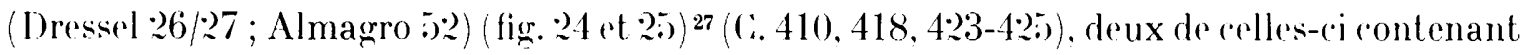
de la poix:8; - amphores punico-romaines (haut. 1 mètre), à panse renllée vers le bas, col très bas et anses soullées a la lève (Almagro 50) (fig. :26)²9. ((C. 415), 419), ayant sans doute contenu de la saumure de poisson, comme les amphores de l'anse Gerhal à Port-Vendres:0 : certaines de ces amphores contenaient des coquilles de peclunculus pilesus ${ }^{31}$ (MM. H. Delauze, M. Pourlevigne, ()FRS).

A proximité : amphore à panse conique ot à pied (fig. 27 ), apparentée au lype 47 de Pelichet.

11. La Madrague de Montredon. - A 600 mètres au large. à l’o. du Cap Croiselte, a -40 motres. Epave punico-romaine du Ife s. ar. o.-C. :amphores de type punique a collerette moulurée (type (i de .laña, 53 d'Almagro) (fig. .28)², jarre ovoüle de la còte

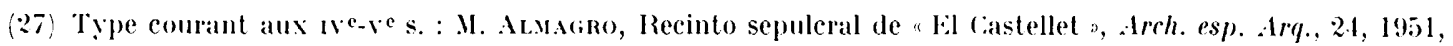
p. 110-111; Las necropolis de Ampurias, 11 (1955), p. 299, fig. 271 et p. 409 ; . N. LAmbocida, Battistero di Albenga, sludi. Ar. Calderini e R. Paribeni, III, p. 735, fig. 5 (19pe A); $\mathrm{V}$. Grace, Amphoras and the ancient Wine Trade (Amer. School at Athens , 1961, fig. 37 a.

(28) C. Gallia, XVIII-1960, p. 13, ?.

(29) Amaniro, p. 30\%, fig. 279 et p. 109 .

(30) rallia, .111-1959, p. 450, figr. 1 .

(31) C. sur cet écaillage des coquillages pour la conserverie, infra 15.

(32) J. 1. . 1. forme de tradition punique ainsi que le montre latlache des anses sur la panse, subit me transformation a l'óponge 

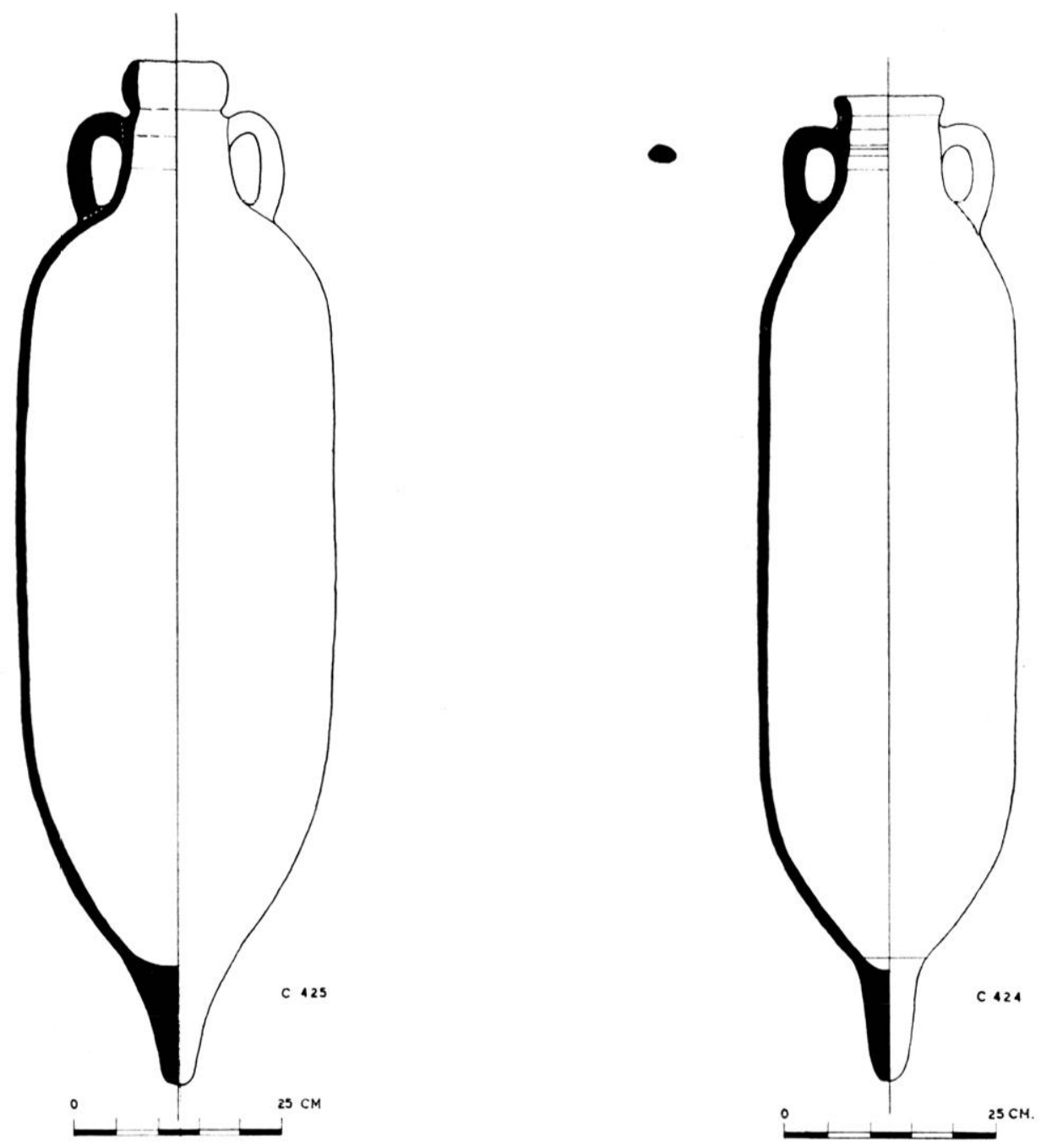

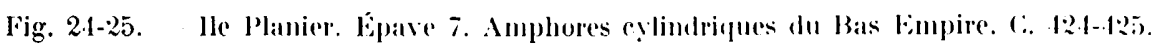

catalane ${ }^{33}$ (fig. 29), associées à une coupelle $e^{34}$ at à une lampe campanienne à vernis noir à réservoir caréné et bec élargi en que ue d'hirondelle (fig. 30). du type de l'Esquilin. analogur a celles du Baou Roux, d'Entremont et du Grand Congloué:.5. L'association de céramique. ibérique postérieure à :066 et d'amphores de Sicile ou de Cirande (iréce a déjà été notée dans l'épave de la (iotat; - bouchon d'amphore (isole) en chaux avere ring cachets de forme ovale (M. J. Cielindo (:. $217,206,216,210)$.

12. Ile Märe $3^{36}$... De l'épave d'amphores it aliques (I)ressel I A) du récif des Farillons,

romaine, par l'adjonction d'un col et d'un pied ; elle est fréquente en Espagne du Sud, dans le .lidi de la Gaule (Ruscino, les Pennes, lintremont (Gallia, XVIII-1960, p. 292, fig. 9), à l'agora d'Athènes (ibid., p. 292, n. 21 ; V. Grack, Amphoras, fig. 38 d) ; elle est absente de la nécropole grecque d'Ampurias, mais a eté signalée dans le cimetiere à inhumation Estruch (M. Armafro, n. c., II, p. 311, fig. 287; cf. p. [409] : forme 53), oul elle ne peut dater du Bas-Lmpire. Cf. F. Bexort, Relations commerciales entre le monde ibéro-punique el le Vidi de la Gaule, Rev. Et. anciennes, 1961.

(33) F. Morret, CVA, Ensérune, pl. 33, 10 ; Bosch-Gmpera, Elnologia de la peninsula iberica, p. 417, fig. 391.

(34) Forme l.aмbogitn 28; 13 du Grand Congloné (L'épale du Grand Congloué, 1961, p. 90 et pl. XI, a).

(35) Cf. L'épave, p. 108 et pl. XVII, 8 .

(36) Cf. Gallia, XIV-1956, p. 28, 6. 


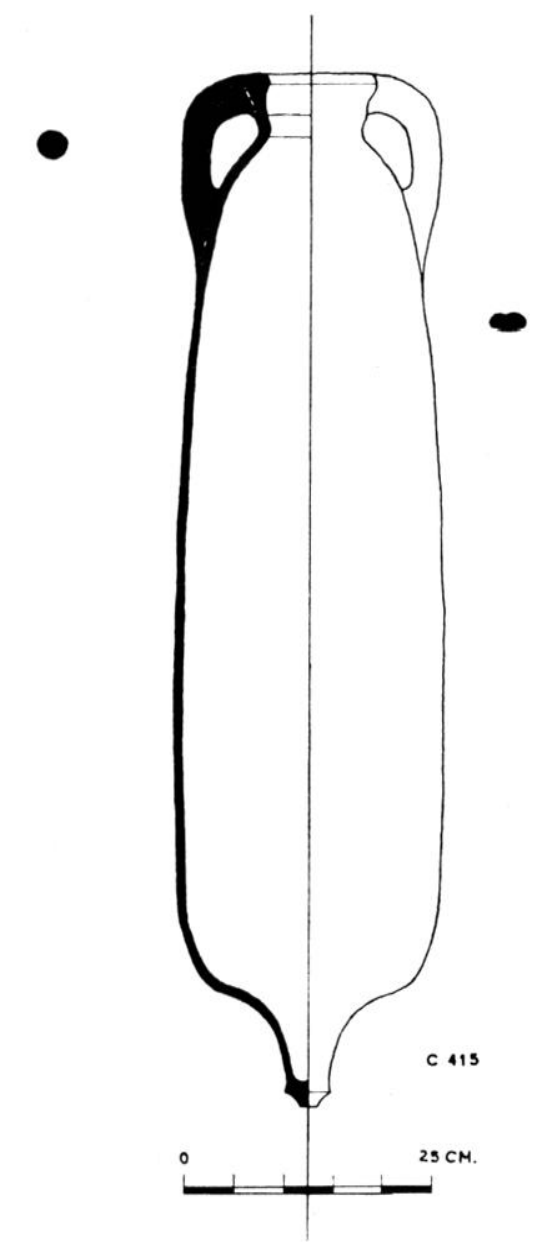

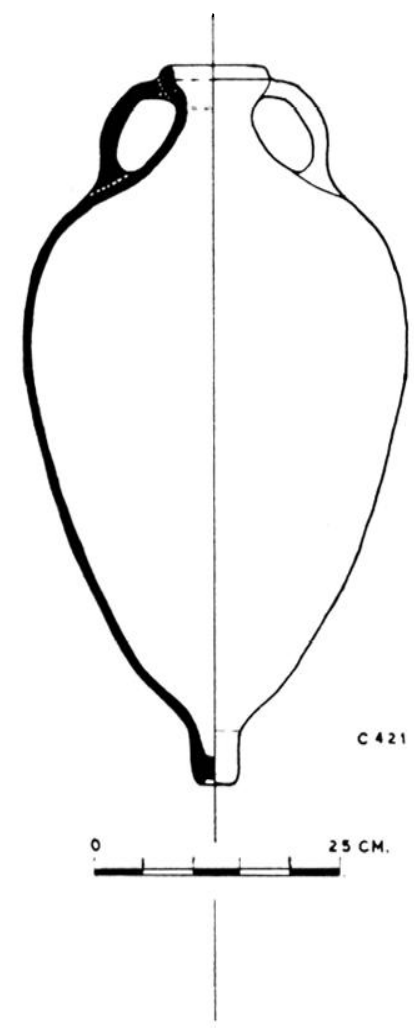

lïg. 27. He Planier. Gisement indeterminé à proximite de l'épave 7. C. 421. Dessins M. Borély.

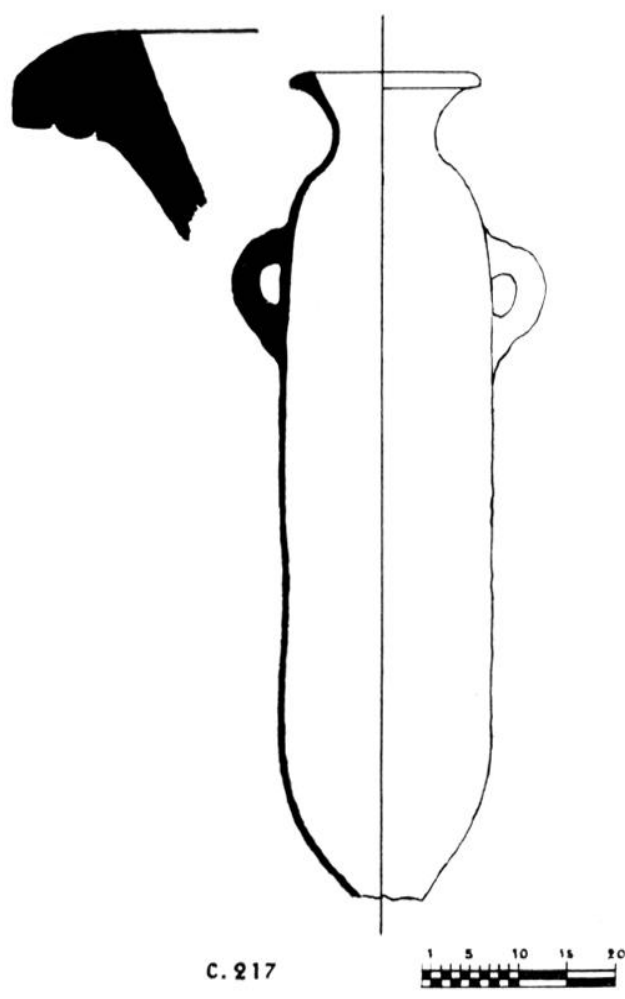

Fig. 26. - La Madrague de Montredon. Amphore punico-romaine a collerette moulurie. C. 217.
Amphore de Bétique à saumure du Bas Empire. C. 415 .
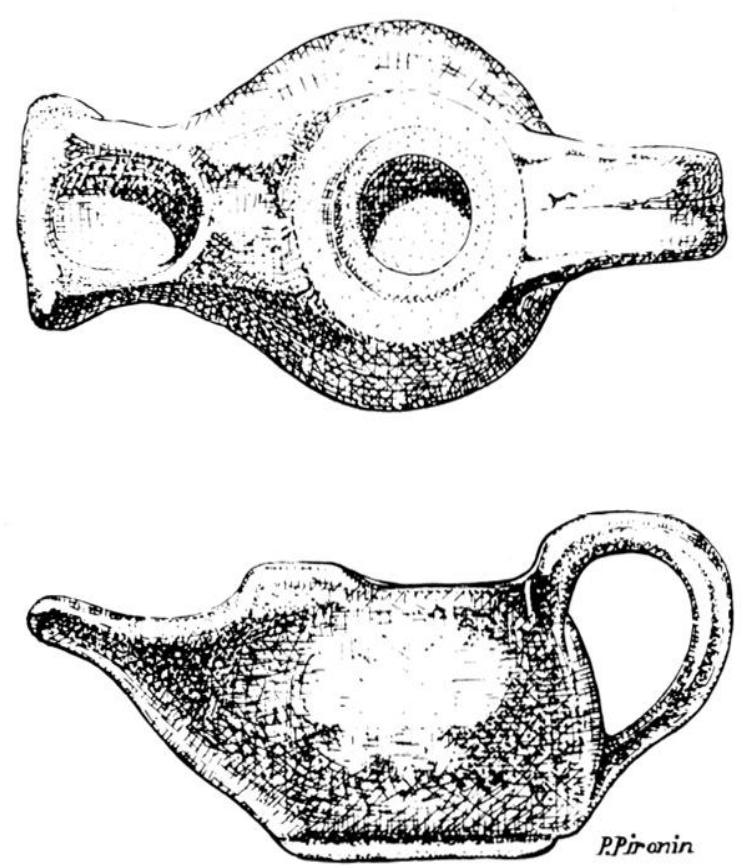

Fig. 30. . L La Madrague de Montredon. Lampe campanienne (11 ${ }^{\mathrm{e}} \mathrm{s}$ ) (long. 0,102 ; haut. 0,04) C. 216 . Dessin P. Pironin.
Fig. 29. - La Madrague de Montredon. Jarre de la còte catalane. C. 206. 


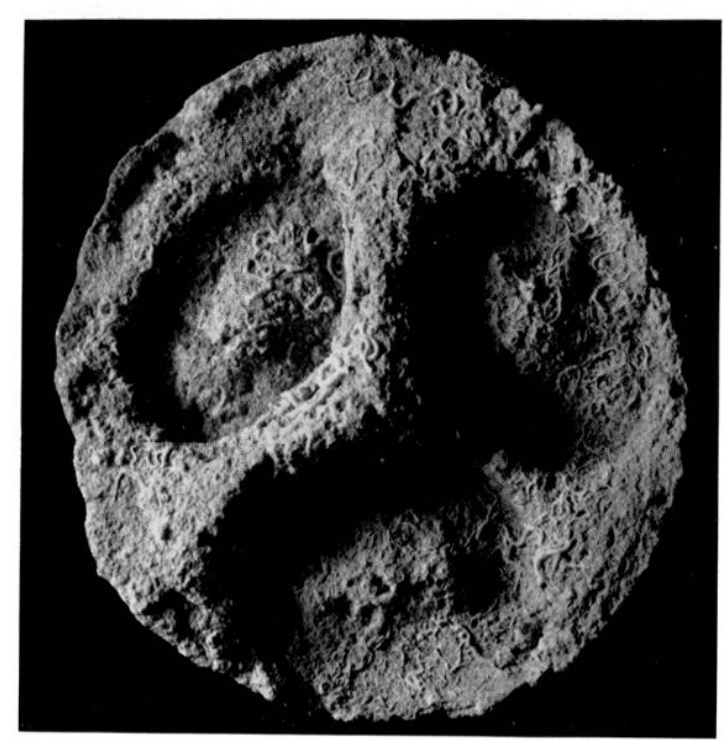

Fïg. 31. He llaire. Epare 3. Bonchon diamphore a cachets ovales (diam. 0.10: (. 375.

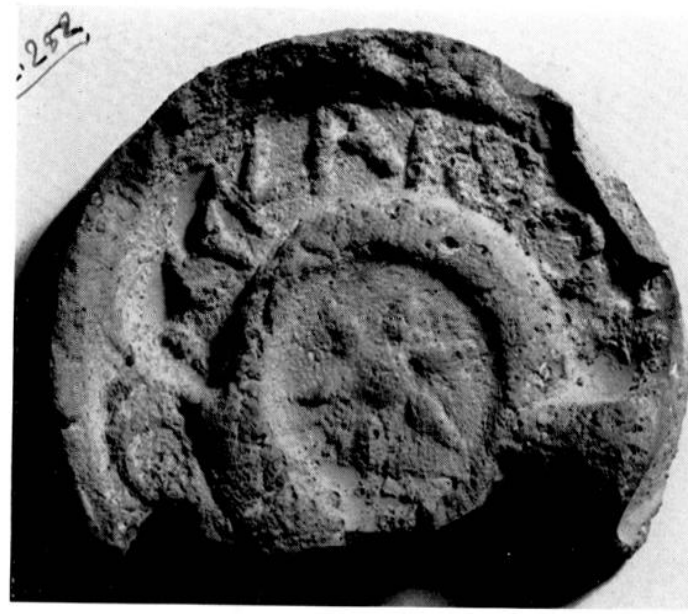

lïg. 3:. He Maire. Epave t. Bouchon d'amphore

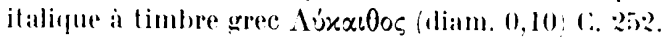

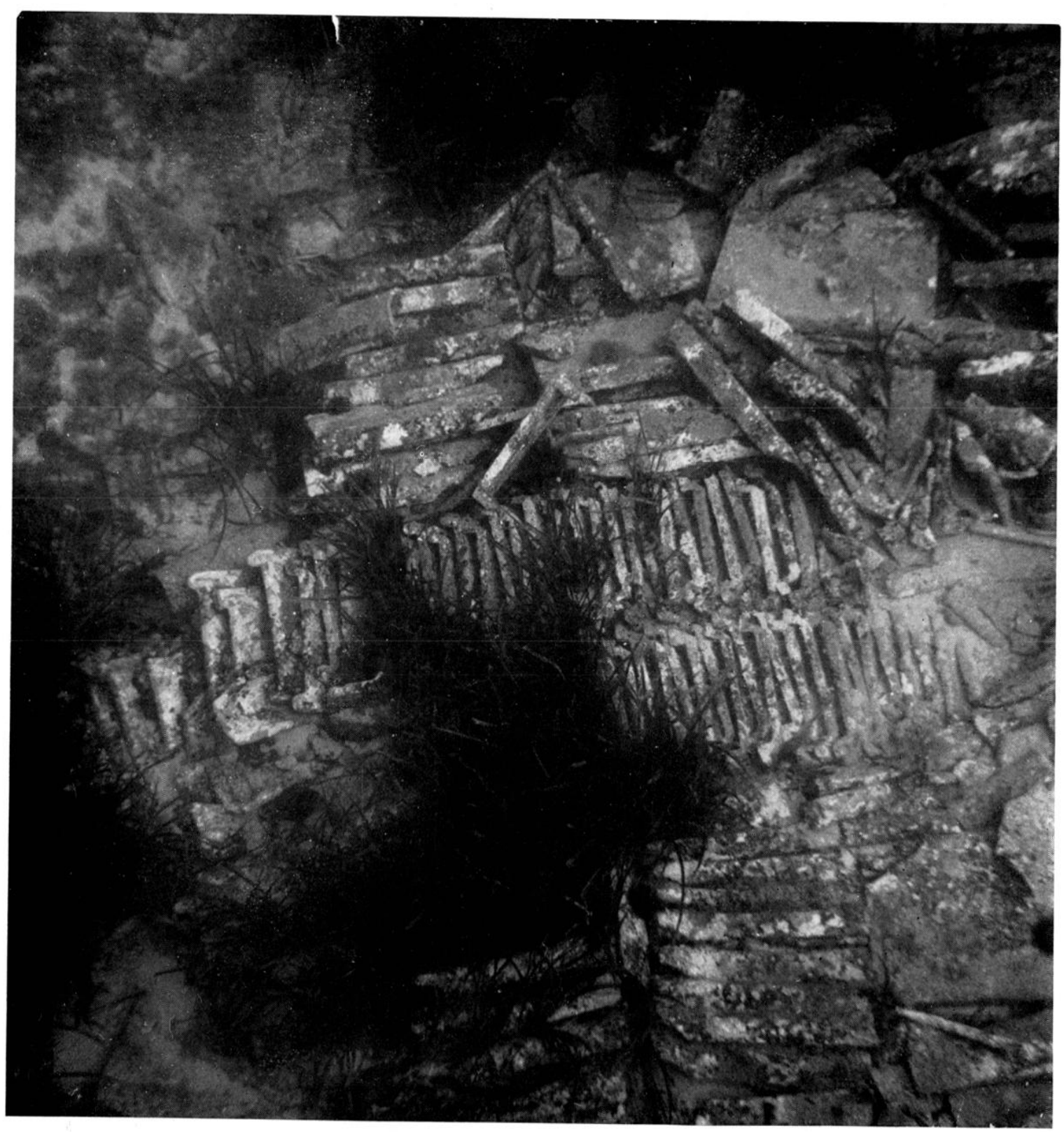

lïg. 33. - - lle du prioul. Lipave de tuiles de l'omegues. (.I. Lassularie. 


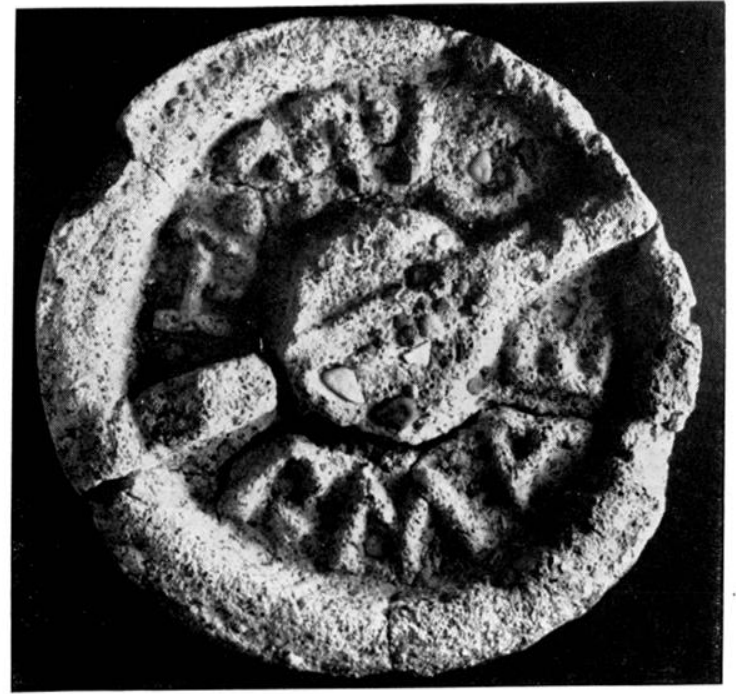

Fïg. 31. He de Jarre. Bouchon d'amphorie italique a timhre de I'. Maep(s) diam. (1.10 (.. 35)3.

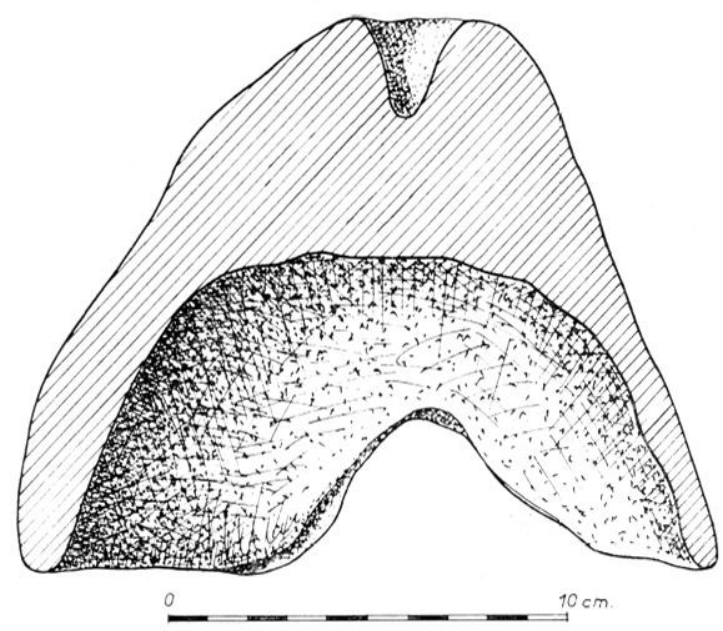

Fig. 37. He de Jarre. Plomb de sonde hemispherique diam. inf, 10,175) (: 331.

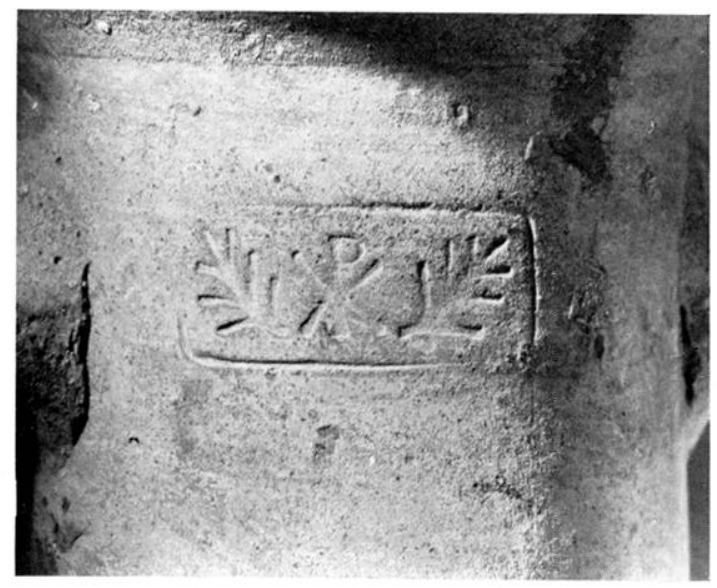

Fïg. 38. -- lassis. Timbre avee chrisme sur col de jarre du Bas-limpire trouve dans le dragage du port ce c: 1.\%. I. Riguir.
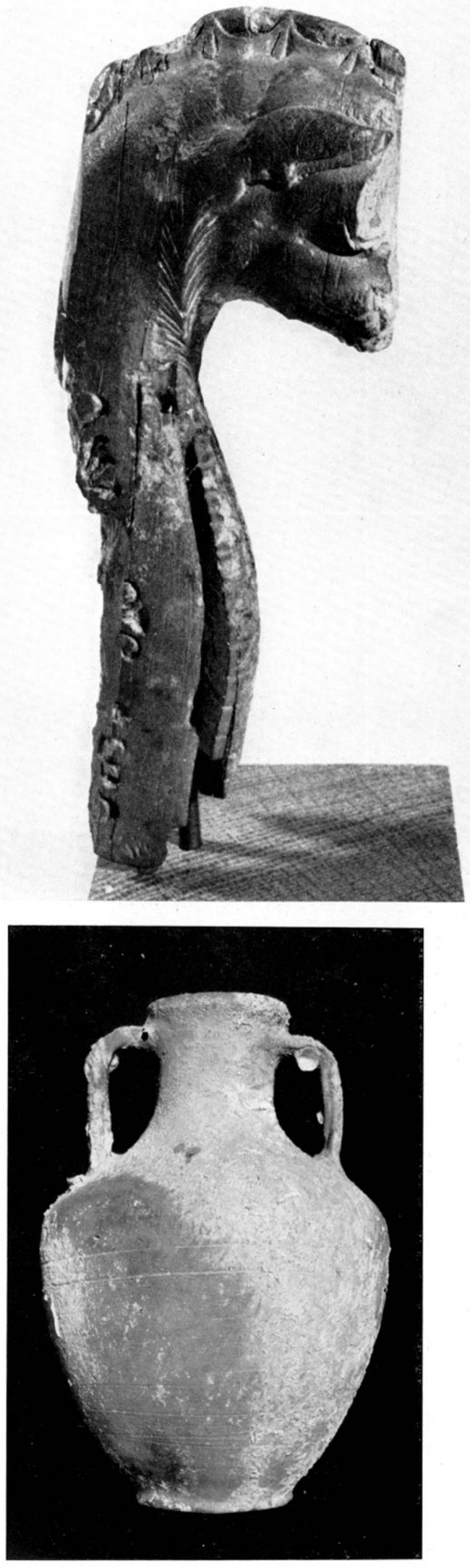

Fig. 35-36. - Ile de Jarre. Jarre et stylide divoire à protome

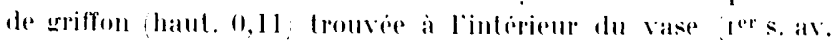

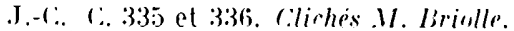


plat à bord rentrant en campanien B avec graffite $\mathrm{V}$ A T, bouchon d'amphore en chaux aver: trois cachets de forme ovale, sans lettre apparente (fig. 31) (M. Poudevigne, (.. 372-37:) ${ }^{37}$.

13. He Mä̈re 4. - Au Sud de l'île, à - 35 mètres, épave d'amphores italiques (I)ressel I B). certaines remplies de noisettes; coupe campanienne B avec graflite gree $\mathrm{X}$ A Y ; fragment de bouchon de chaux attenant à un col d'amphore italique, avec timbre gree $\Lambda$ Y K A I $\Theta O \mathrm{Y}^{38}$, inscrit autour d'une étoile à six rais (fig. 32) (М. .J. Cielindo, C.. 311-313, $2:)-2: 56$ et 326$)$.

14. Iles du Frioul. - - Au N.-()., de Pomègues, entre la pointe de Ciarapègue ct l'ìlot de la Luque, à - 16 mètres. épave de tuiles dans leur lit de pose de chargement (fig. 33) (.M. Lassalarié. Domenge, Capetti : (. 296).

15. Archipel de Riou. - Du "cimetière marin " de l'Esteù dou Mièi ${ }^{39}$, entre lés îles Jarre et ('alseragne : amphore italique (1)ressel I B), remplie de valves inférieures d'huitres (spondylus gaederopus). écaillées pour être conservées dans la saumure ${ }^{40}$; cols de même type, à lèvre très haute ayant conservé le ur bouchon de chaux (position des lettres à l'inverse de la normale) aux noms de P. II A E//G. I. I. L. m (fig.34) (J. Gelindo (.. 330, 341, 353. 356, 363). Le nom de $\mathrm{M} \mathrm{A} \mathrm{H} \mathrm{E} \mathrm{(s)} \mathrm{avec} \mathrm{ligature} \mathrm{des} \mathrm{deux} \mathrm{dernières} \mathrm{lettres} \mathrm{se} \mathrm{retrouve} \mathrm{sur}$ les timbres estampés au col d'amphores de même type à Fos et au cap Sperone en Corse' ${ }^{41}$. Il figure dans le répertoire des noms de potiers d'Arezzo (esclave Mahes de l'atelier d'Ateius ${ }^{42}$; - protomé de griffon en ivoire, ornée de palmettes, trouvée dans le dévasage d'une cruche du I $^{\mathrm{er}}$ s. ar. J.-(C. (fig. 35) et 36), sans doute stylide ${ }^{33}$ d'ivoire, lutela navis ebore caelala $^{44}$ (M. Y. Pernac, (.. 335)-336); - plomb de sonde hémisphérique (calapirales, bolis) dont la cavité inféricure était garnie de suif pour prendre l'empreinte du fonds ${ }^{45}$; le sommet, muni d'un anneau de fer, disparu (fig. 37) (M. J. Gelindo, (.. 331).

16. Cassis (Carsicis). - Le dragage du port de Cassis a permis de recueillir des fragments d'amphores, à la cote - -9 , sous 4 mètres de vase, en majorité du Bas Empire : céramique de la Graufesenque; amphores du sud de l'Espagne à col évasé (DresselPelichet 12/48), du type de celles de l'épave de l'île du Levant ${ }^{46}$; sphériques (I)ressel 20). Timbre d'époque chrétienne sur un col, le chrisme entouré de deux palmes (fig. 38) appartenant sans doute à une fabrique locale; le timbre est à rapprocher du chrisme de l'autel chrétien de Cassis, du ve s. $(F O R, \mathrm{~V}, 6)$.

1\%. Calanques. - A l'O., de Cassis, à la pointe Cacau, entre Port Miou et Port Pin,

(37) Nombreux exemplaires de ce type de marque carrée ou ronde : Gallia, NVI-1958, p. : 28, fig. 32 et 33; XVIII-1960, p. 44, fig. 5.

(38) Forme provinciale, avec diphtongaison et chute du v devant le 0 de Ij́x.xv0os (Xénophon, Hellén., 6, 3, : ?) ;

W. PAPE et E. Binstiler, Wörlerbuch griech. Eigennamen, II, p. $\times 20$.

(39) C.f. Gallia, NVIII-1960, p. 11, 2.

(10) Supra, no 10.

(41) Gallia, XVI-1958, p. 37, 7 et n. 84 et p. 39, 5 .

(42) J. Déchelette, Vases céramiques de la Gaule romaine, I, p. 13 ; Oswand et PRrcr, Terra sigillala, p. 6.

(43) Cf. Svoroxos, Stylides, ancres hierae, aphlasta, stoloi, totems marins, Journal inlernal. d'archéologie numismalique (Athènes), 16, 1914, p. 94 ; R. de LaGardière, l'́tudes sur la marine ancienne, Trilon (Pan is), 57, 1961, p. 6.

(44) Śxį̀ue, Epist., 76, 16 ; cf. la tête d'Artémis de Fos : Rev. El. ligures, 18, 1952, p. 287, fig. 47.

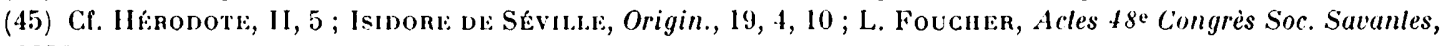
Inijon, 1959.

(46) Gallia, XIV-1956, p. 29, 10 et fig. 7, 11-13. 

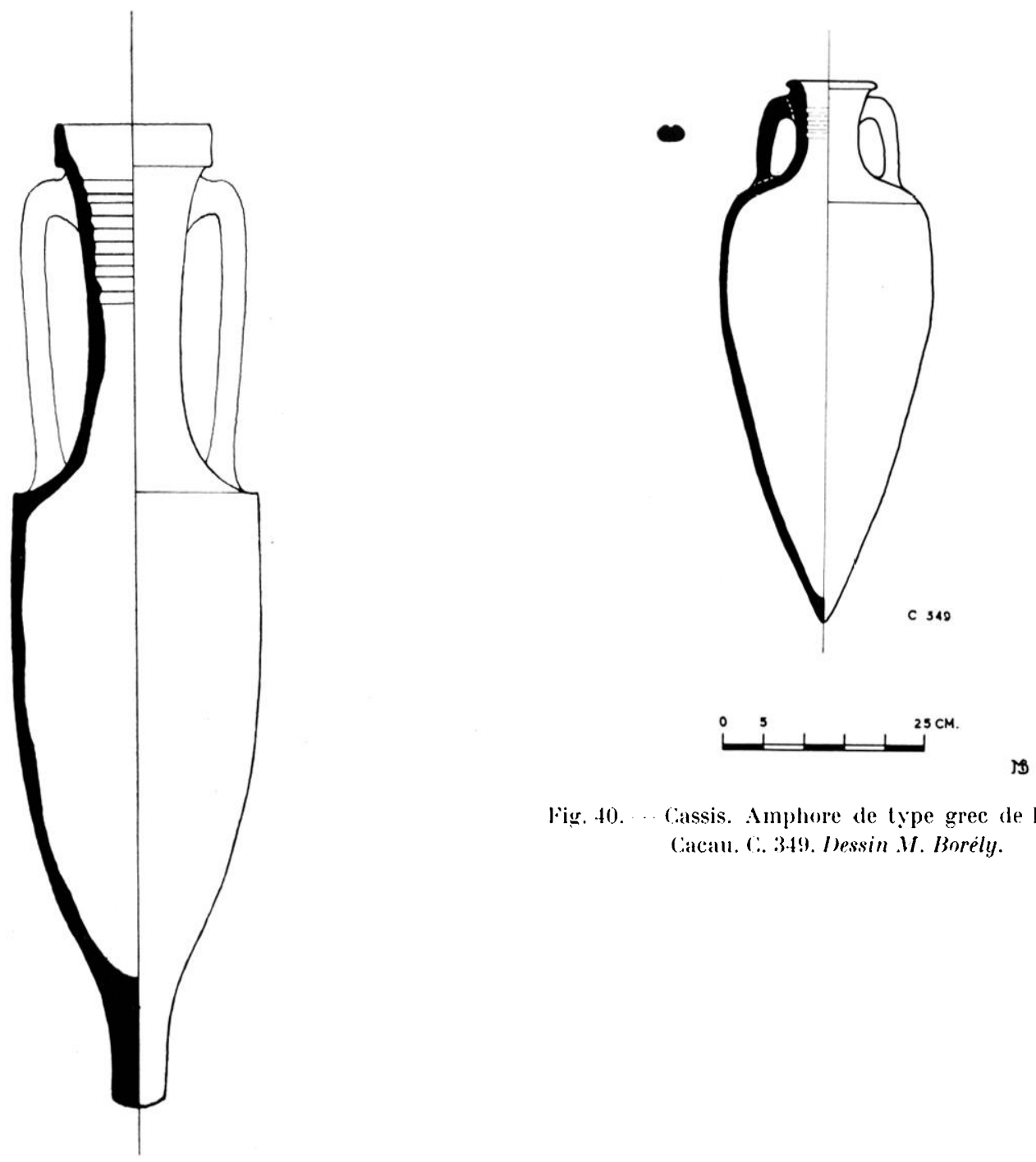

Fig. 40. . Cassis. Amphore de type grec de la pointe Cacau. (.. 349. Iessin . M. Borely.

c 232 (Cassis)

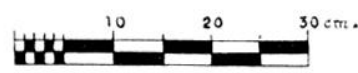

«.- Fig. 39. Cassis. Amphore italique de la pointe Cacall. (.. 23:.

a -35 mètres, sur fonds de sable épave (pillée) : quelques amphores italiques (Dressel I B) (fig. 39) et entre des failles de rocher amphore piriforme à anses bifides et col court terminé par un bourrelet ${ }^{47}$ (fig. 40) (MM. Y. Girault, J. Manganelli, C. 232, 319, 349, 350 et musée de ('assis). - A la pointe E. du Cap Morgiou, jas d'ancre avec armature de bois (long. 0,80) (.I. J. Manganelli : muséc de Cassis).

18. Cassidaigne. - Au N.-N.-O., à 90 mètres du récif (balise), à -30 mètres, "cimetière marin ": fragments d'amphores pseudo-rhodiennes (Dressel 43/45); épave d'amphores italiques (Dressel I B), pillée en 1959 (N. H. Portail, C. 180-183). En 1961, la prospection du gisement a permis de retrouver quelques amphores italiques intartes (Dressel I B et

(17) Sa forme la rapproche d'une amphore plus petite (haut. 0,43 a a anses coudées, grisée par la vase, du "plateau des chères" (Gallia, XVIII-1960, fig. 3: ; celle de Cassis a une pàte rose très fine, analogue à celle des amphores tardives de Chios et de $\operatorname{Cos}(B C H, 7 \overline{7}, 1953$, p. 142). 


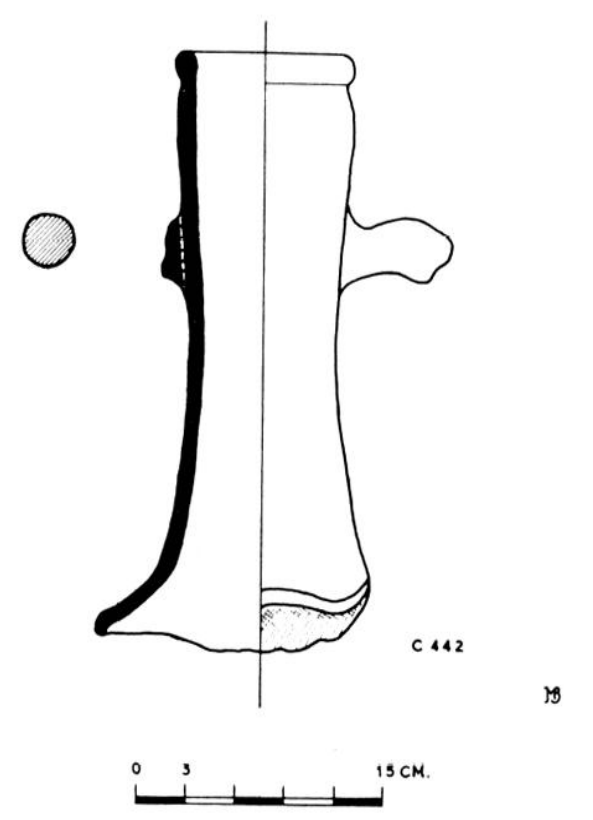

Fig. 41, - Cassidaigne. Col damphore grecyue

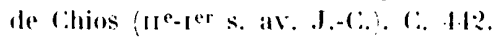

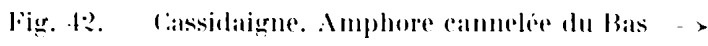
limpire. (:. 138 et 119.

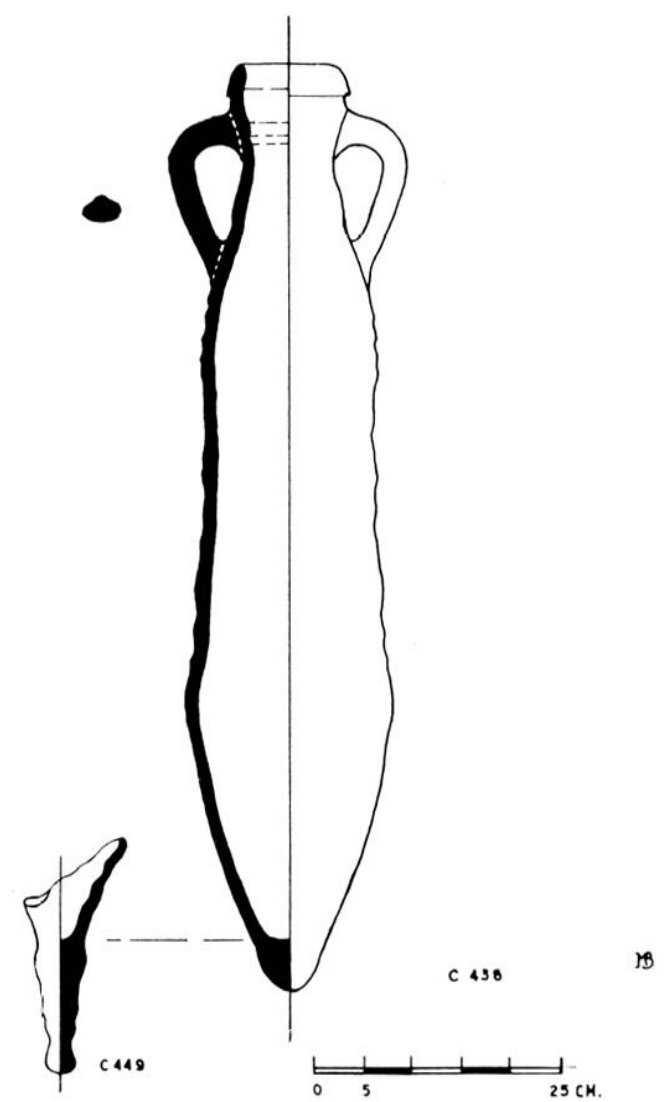

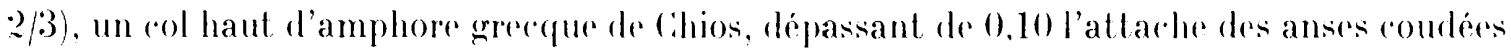

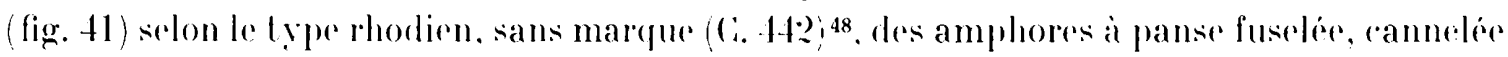

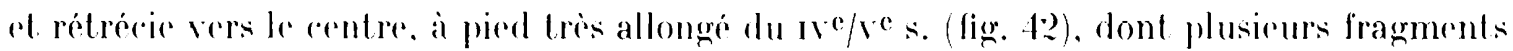
de même type ont été trouvés dans le dragagere du port ${ }^{49}$ (.I. .J. Manganelli, C. 16:1-171, $177-178,437-448)$.

Au Nord du récif, à j) kilomètres au large entre la Ciotat et Cassis, à 4i) mètres, moyeu de plomb scmblable à celui du récif des Émaillades (île Maïre) ${ }^{50}$, armé d'une frette de fer encastrée dans une rainure sous la tranche du disque supérieur (II. Ci. Beuchal. (.. 314) (fig. 43 et 44); il étail traversé par deux larres de fere en croix, maintenues par un pivot central de fer. La découverte de piéces analogues, plus trapues, aux iles Medaston,

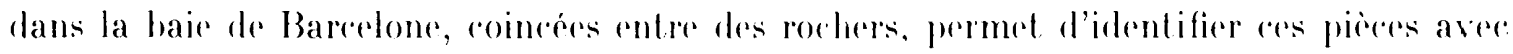

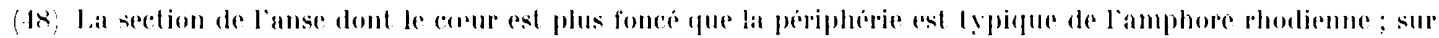

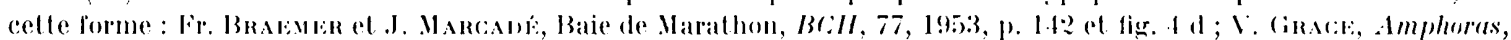

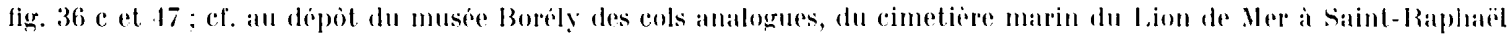

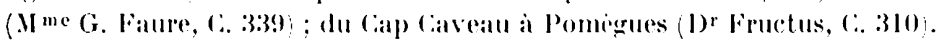

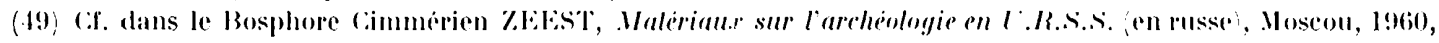
pl. 40, figr. 10:3.

(50) l. Épave du cimand congloue, p. 187, fig. 101.

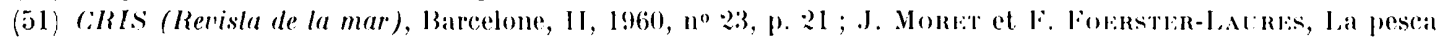

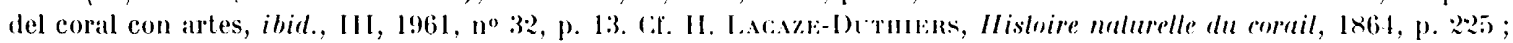

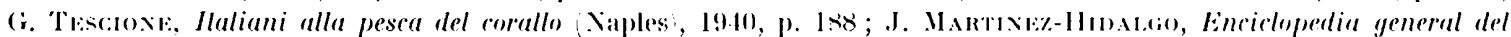
mar, 1957, s.5. anganela, I. 1. 2.49 ef 11, p. 19.4. 

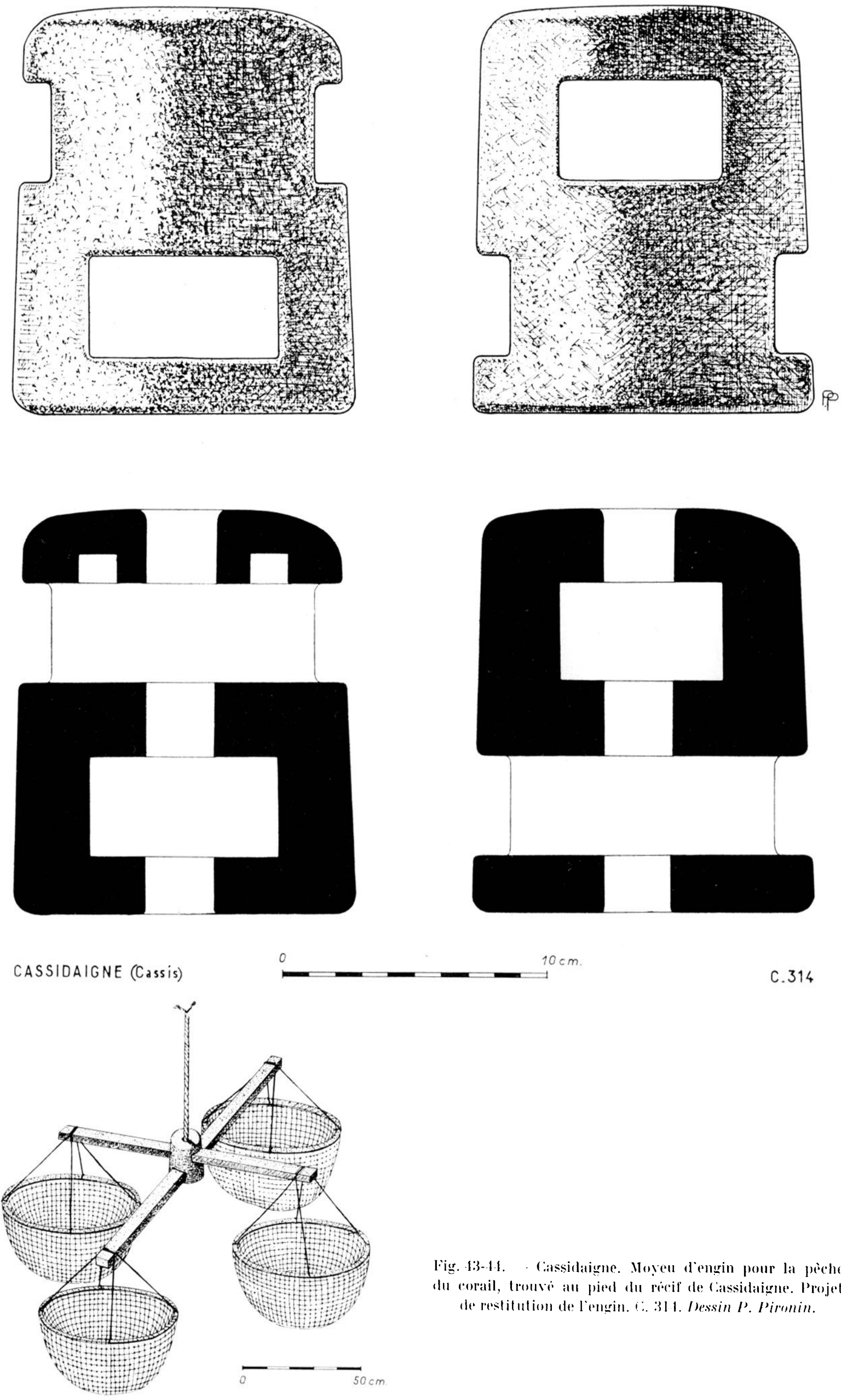

liig. 13-14. - Cassidaigne. Hoyen dengin pour la pèche du corail, trouve an pied du recil de Cassidaigne. Projet de restitution de l'engin. 6. 311. Dessin P'. Pirmin. 


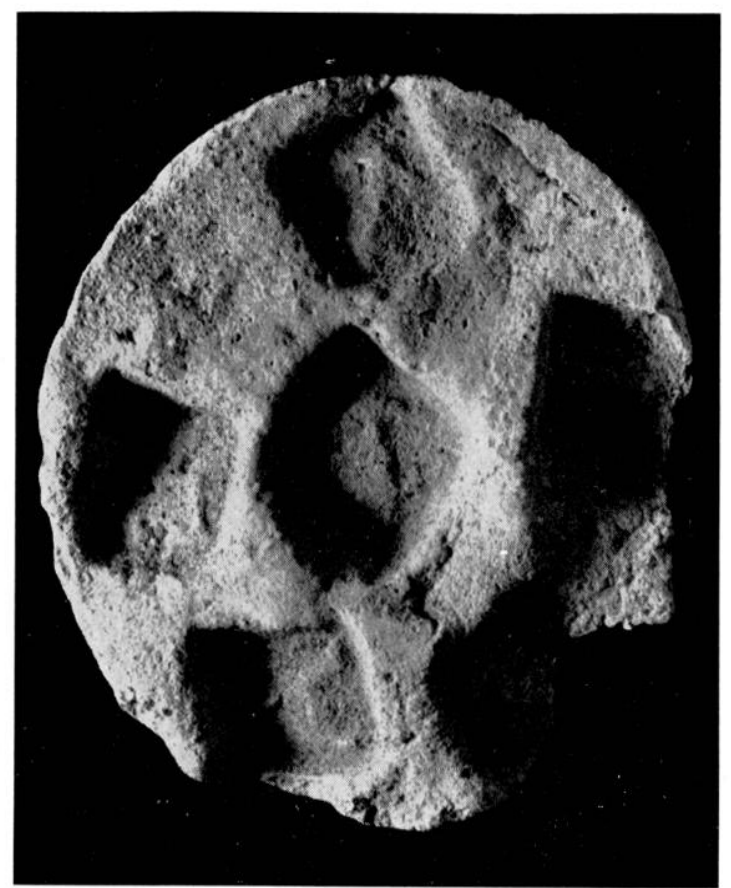

Figr. 15. La Ciotat. Bipave I du Canomnier du Sud. Benchon damphore a timbres carres portant des lettres

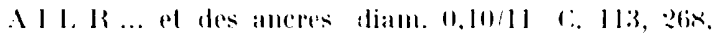
$: 39$.

les "engins" pour la peiche du corail ; aux bras de la roix étaient suspendus des filets montes peut-ètresur une armature de plomb (moyer de l'ile lläre) ou groupess en faiscean ou fauberl dans les engins modernes, pour recueillir le corail délaché de la paroi rocherese (enelli retibus) ${ }^{52}$ par la traction do l'engin manouvé do la harque par les corailic urs. Ca cylindre de plomb. fue sa technique apparente aux jas d'ancere helléniques. sera remplacé à l'époque moterne par une masse le plomb. une pierere on une dalle perese de eimy 53 . peul-eitre aussi de trois trousts.

19. La Ciolal (Kitharisha).

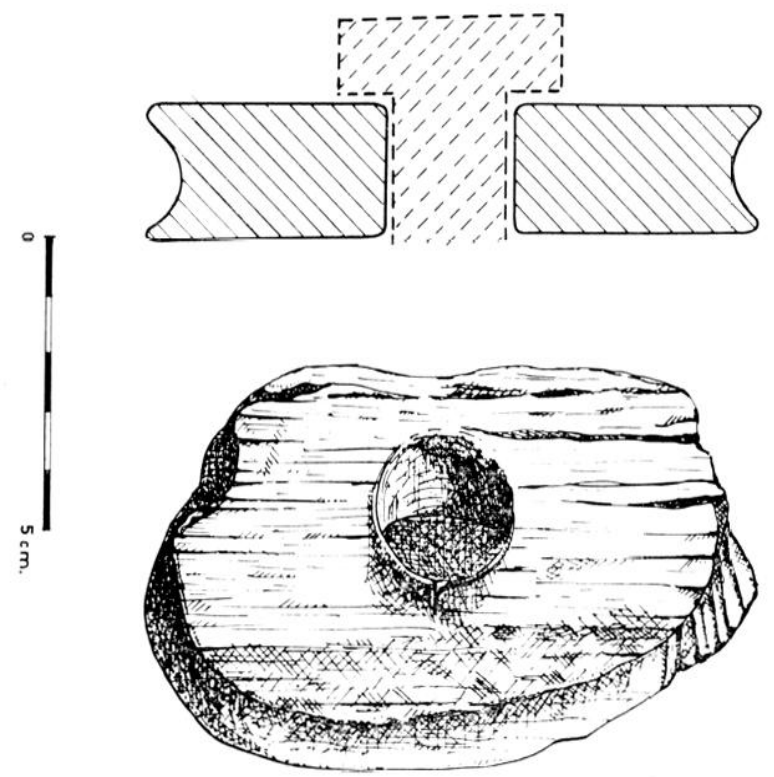

Fig. Hif. La ciotat. Bpave I du Canonnier du sud.

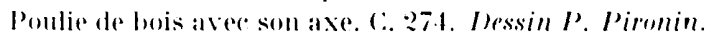

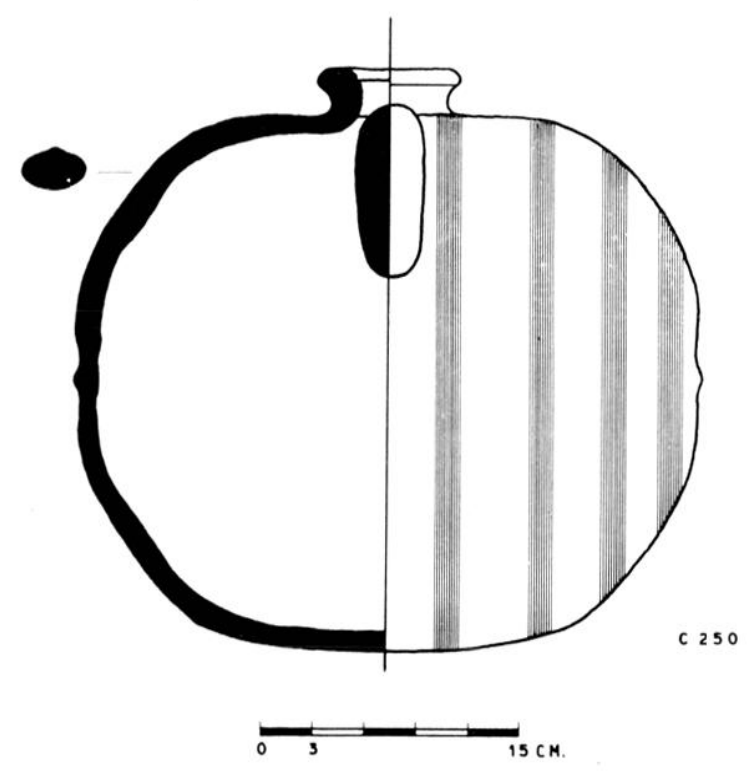

liig. 17. Port-tipes. Tomnelet du Bass limpire at panse liletien. 1.: $: 50$.

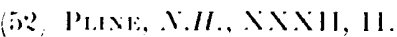

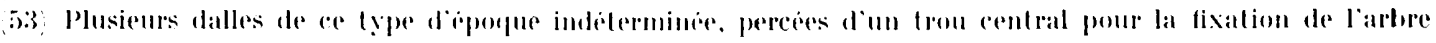

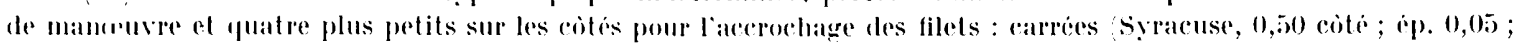

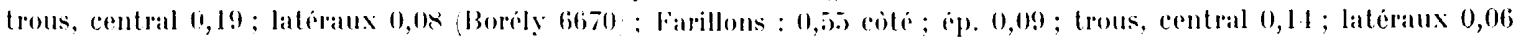

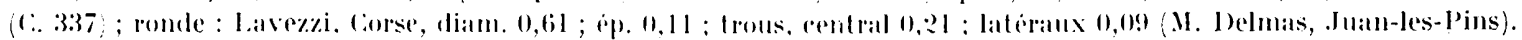

(5.) sinpru, no 1, n. 15.

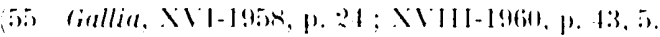


permis d'identifier d'autres amphores de mème type ot de recueillir des céramiques, qui ronfirment la datation : campanienne A $(C: .26: 2.999)$; - petite urne en gris ampuritain a cannelures (c. Pos) ; - urne cinéraire en plomb, écrasée ; bouchons d'amphores en chaux.

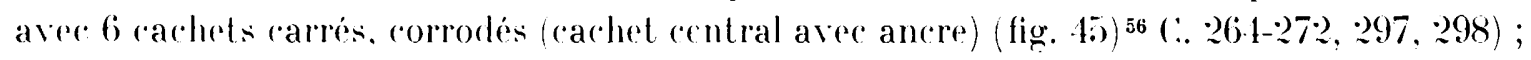
- Luyau de plemb; - pièces de gréement en bois (poulie avee son axe (fig. 46) (6. 274) et bitte d'amarrage (II. II. Portail, musée Ciotaden).

La prospection de M. Y. Lucas a repéré huit jas d'ancre en plomb, autour de l'lle Verte; trois de reux-ci au musée liotaden.

\section{VAR}

20. Saint-Cyr. -... Epare d'amphores italiques a la pointe Grenier (Cidt des Douanes J.. Joly).

21. Le Brusc (Tauroentum). E. Épave au pied du récif des Magnons, à 150 mètres de l'ile des Embiez. a 30 mòtres. Amphores de types différents : a col coll bourrelet et anses

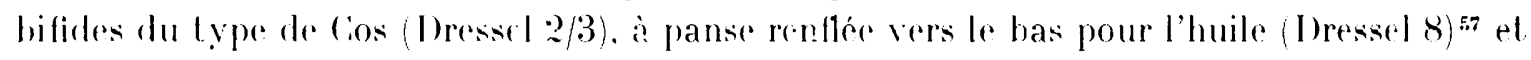

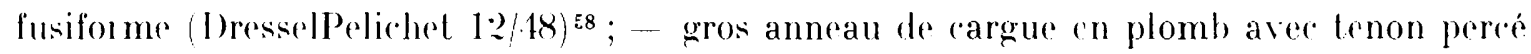

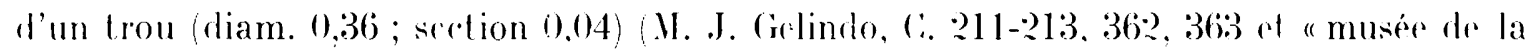
mer" P. Rirard aux Limbiez).

22. Iles d'Ilyères. Porquerolles. - A la pointe des Medes, au S.-O. de l'ille, au pied d'un récil à fleur d'eau, - 18 mètres, épare de tuiles étalée sur une surface de : 20 mètres long. (.1. I) memenge, ( :. 389).

23. L'épave de la pointe du Langoustier ${ }^{59}$ a proximité de la balise de la Jaumegarde. a -2.) metres est etudiée par Ir groupe d'entreprise des Travaux immergés du Mlidi (II. J. Arri).

24. Port-Cros. - 1)ans la haie de Port-Man. à - 20 metres, tonnelet de terre cuite a deux anses (long. 0.38) (fig. 47) du Bas Empireco (M. William Xignesse, (. .50).

25. Ilot de Bagaud. .. I)u "cimetière marin " déjà signalé dans la passe, amphores à fond plat [Dressed 30 ; Pelichet 47) du $111^{\mathrm{e}} \mathrm{s}$; ; a col conique cannelé et anses remontantes (fig. 18), analogues à celles d'Athènes et de Niederbieber du Bas Empire, et à panse fusiforme très allongér (fig. 49-50) analogues à celles des voùtes des mausolées de Galla Placidia à Ravenne of du baptistère d'Albenga (CERS de Toulon et coll. particulières, d'après les releves de. II. R. Itiot $)^{61}$.

26. - Saint-Tropez (Alhenopolis). Au cap lamaral, épave l'amphores italiques

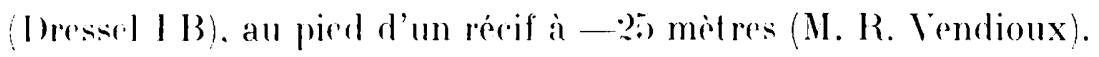

(56) Mbid., N1111-1960, p. 44, tign. 5).

(57) C. Rev. El. lig., 18, 1952, p. 145, fig. 11, p. 228, fig. 8:3 ; Gallia, XV1-1958, p. 20, fig. 1!.

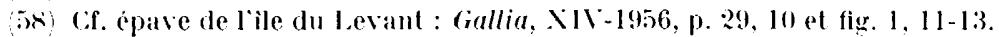

(5) Cf. (iallia, XV1-1958, p. 26, 4 el fig. 30-31.

(60) Tommelet analogue an musce de Mayence: A. Grkxise, Man. Arch., II, p. 601-4, lig. 202.

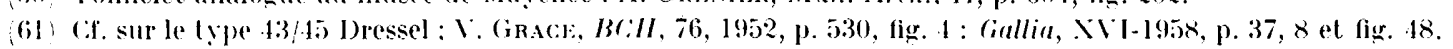

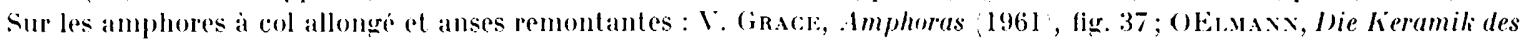
liastells Niederbieber, pl. 47, 1 : analogues a col court a Varathon $B 6: 1,77,1953$, p. 114, fig. 6. Sur les amphores

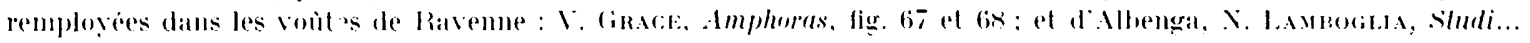
1. Calderini el R. Paribeni. III. 1. ה11 type F et stupra Is. 


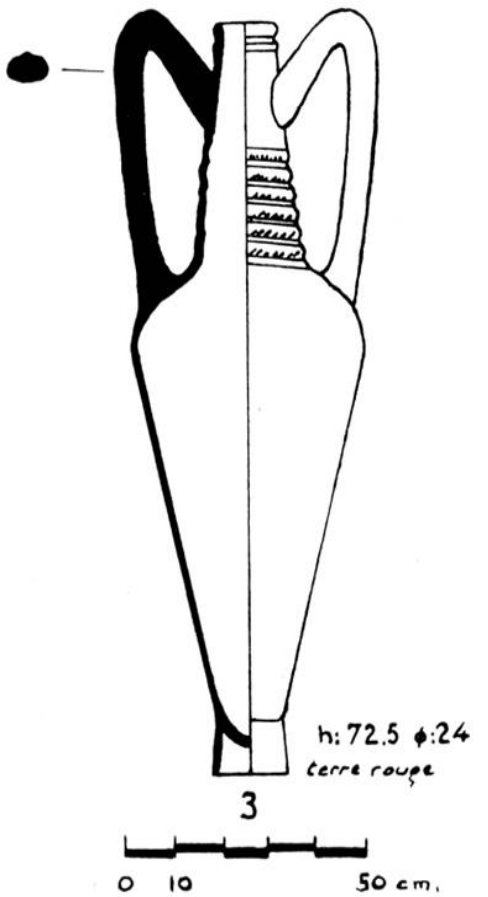

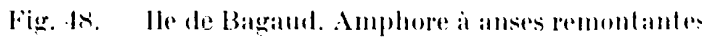
dul Bas limpire.

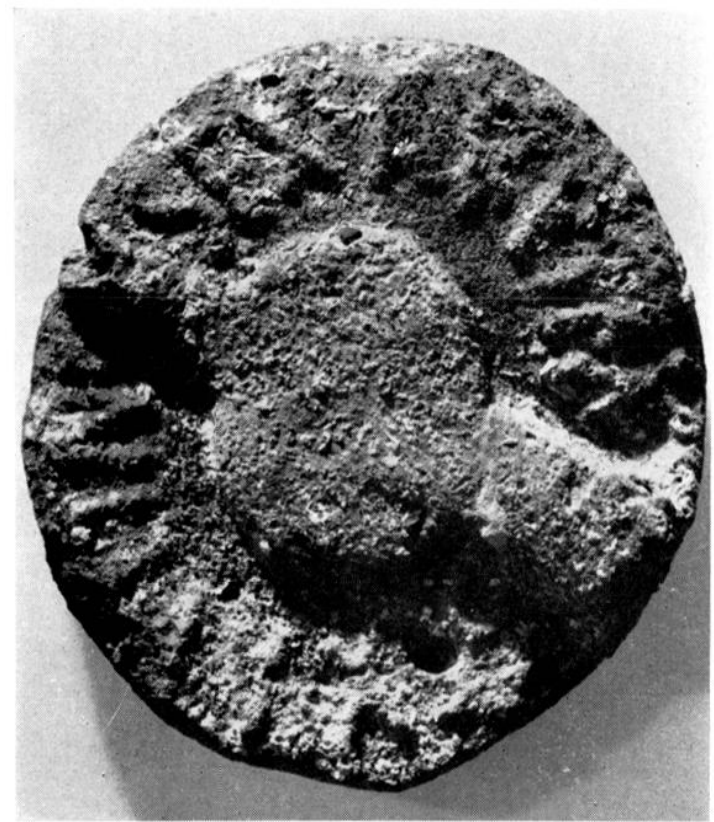

Firg. sl. Le Dramont. Bouchon d'amphore de serlius Arrins diam. 0,095: ep. 0,01:. Vlusíe de la mer, Saint-Raphatit.

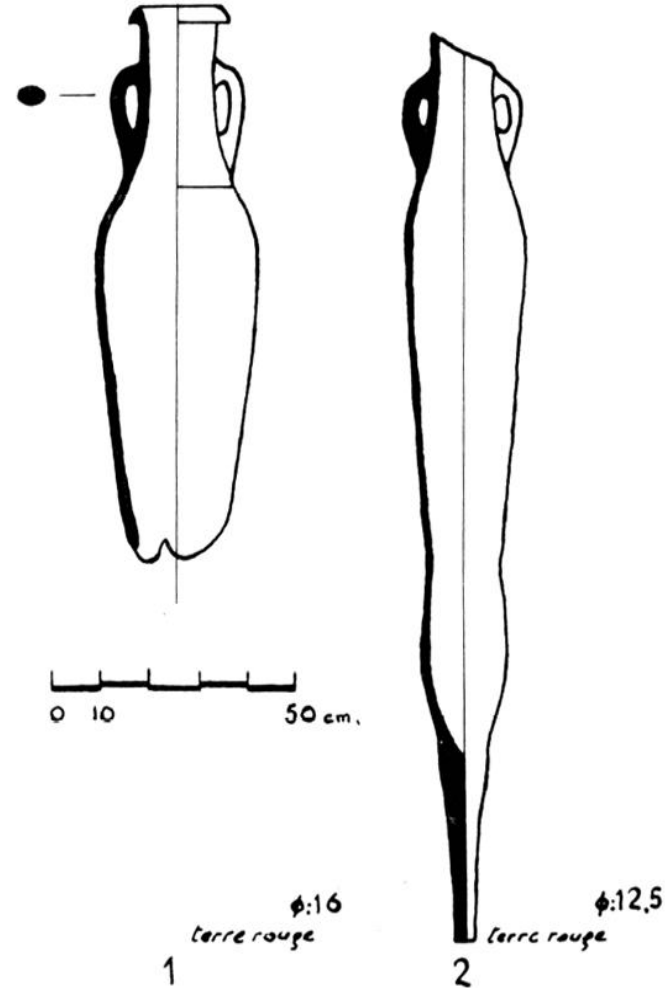

Fig. 19-5). - Me de Bagraud. Amphores fusiformes du Bas limpire. lessins lR. Iniot.

2\%. Saint-Raphä̈. I'épave 1 du tramontce recouverte par le sable, a ete a noweau lobjet de pillage. Bourhon d'anphore en chaux : SE X. ARRI(us) IIF (.1/arei filins) (liz. 51) qui apporte un élement interessant à l'épigraphie de are grisement (I. Cogrliévina : musée de la mere ¿. Saint-Raphä̈l).

28. Igrul-. Intheorr. L'ópave d'amphores it aliquess an nom des Lassii, du ler

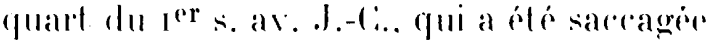
par des lonilleors dandestins, a des bois rollon inat de conservation : type de earione a cont re-quille ou carlingue ; membrures a maille irréxuliere, altenantes aux horless el all phancher ou vaigrage en partic conserves

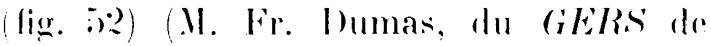
Toulon).

(i2) Ciallia, N11-1958, 1. 17, 2; N1111-19661, 1. 51.

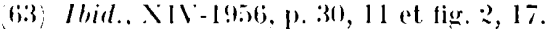




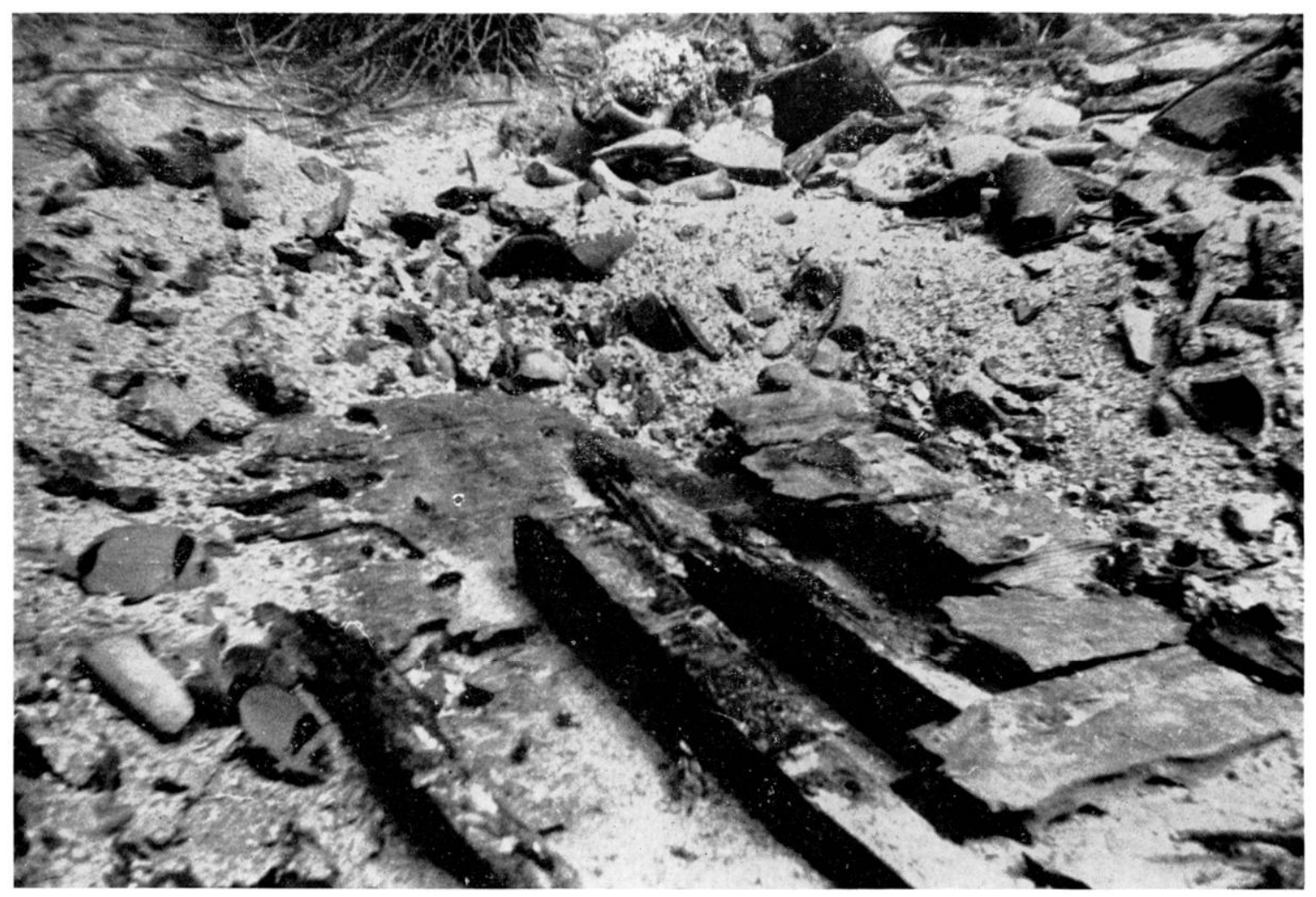

IFig. 52. Agay-Anthéor. F́pave I de la (Chrótienne. Ia membrure avec son vaigrage. Cl. Fr. Inumas.

ALPLS-MARITIMES

29. Ile Sainte-Marguerite. - A 80 metres de l'ìle. sur la còte X.. a l'o. du Fort, face a Cannes, à 1: midres, emblema de mosaïque polychrome. régulièrement découpé, representant l'enlevement d'Eurupe. en bon état de conservation (fig. 53). L'année suivante, au pied du tombant, lampe de bronze en forme de canard (fig. ij4) ${ }^{64}$. La distance de la còte rend invraisemblable l'hypothese de l'effondrement d'une villa ${ }^{65}$ : jet a la mer ou épave dispersée et recouverte par les algues ? (IL. (i. Barnier et R. Cialame).

30. Intibes (Antipolis). Au pied de la falaise de la (iaroupe. au promontoire de Tirapei avait été reconnue à - 8/1: mótres, une épare d'amphores a anses bifides du type de Cos (I)ressel 3) de l'époque d'Auguste et de grands dolia à armalure de plomb. avec: leur couverele ${ }^{66}$. Lin petit delium porte une marque estampée sur deux lignes (fig. is) at $5(6)$ :

$$
\text { (i. PIRAIVS//CER I) O FE(: (it) }
$$

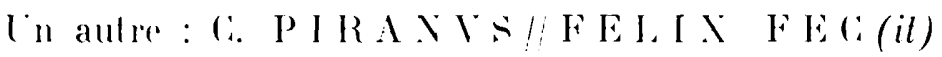

Le nom de Cerdo étant fréquent en Campanie ${ }^{67}$. il est vraisemblable d'attribuer la

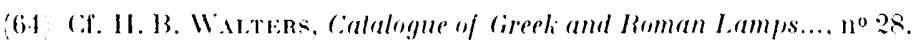

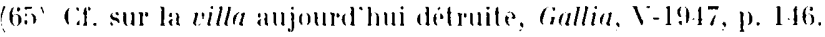

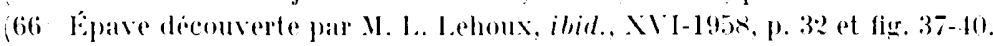

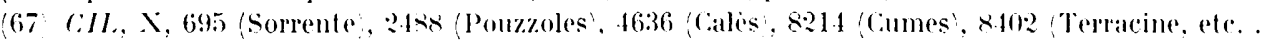




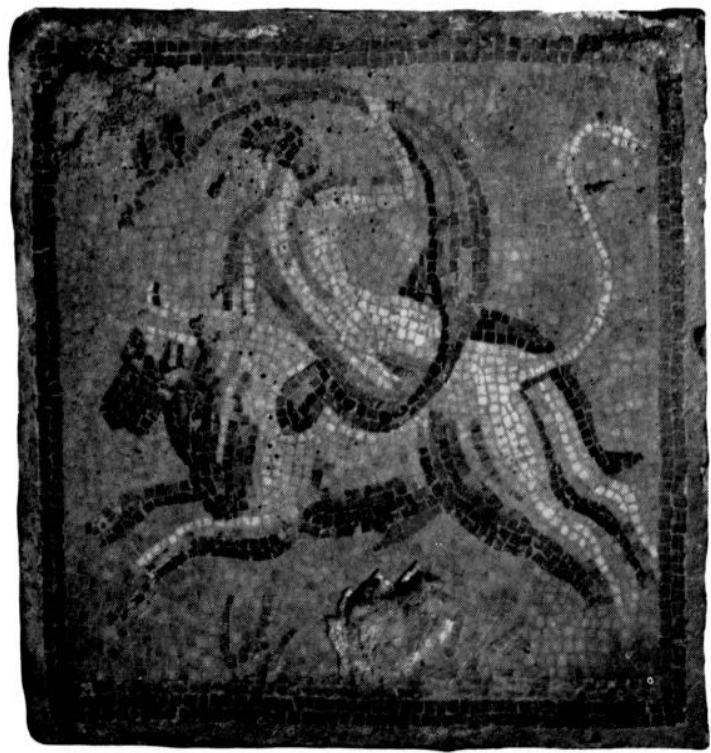

Fiy. 53. - Camnes. Fipave (? de l'île Sainte-Narguerite Eimblima de mosaïque : enlevement d'Europe $0,38 \times$ 0,29). (.I. du r:lub sotus-marin de Pau-Océan.

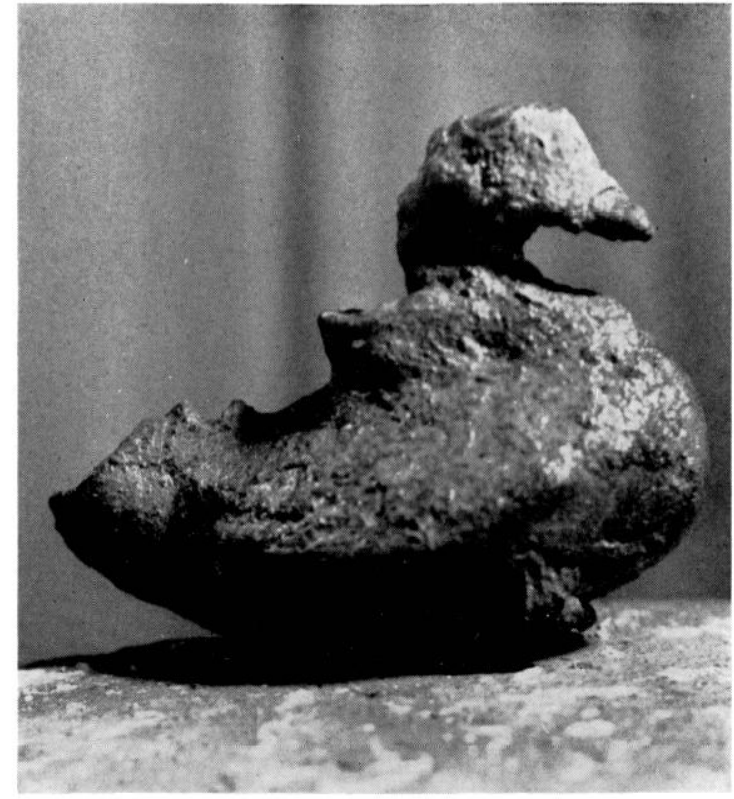

liig. 5.1. - Cannes. Lampe de bronze en forme de canard provenant du mime gisement. C.l. G. Barnier-stévénino.
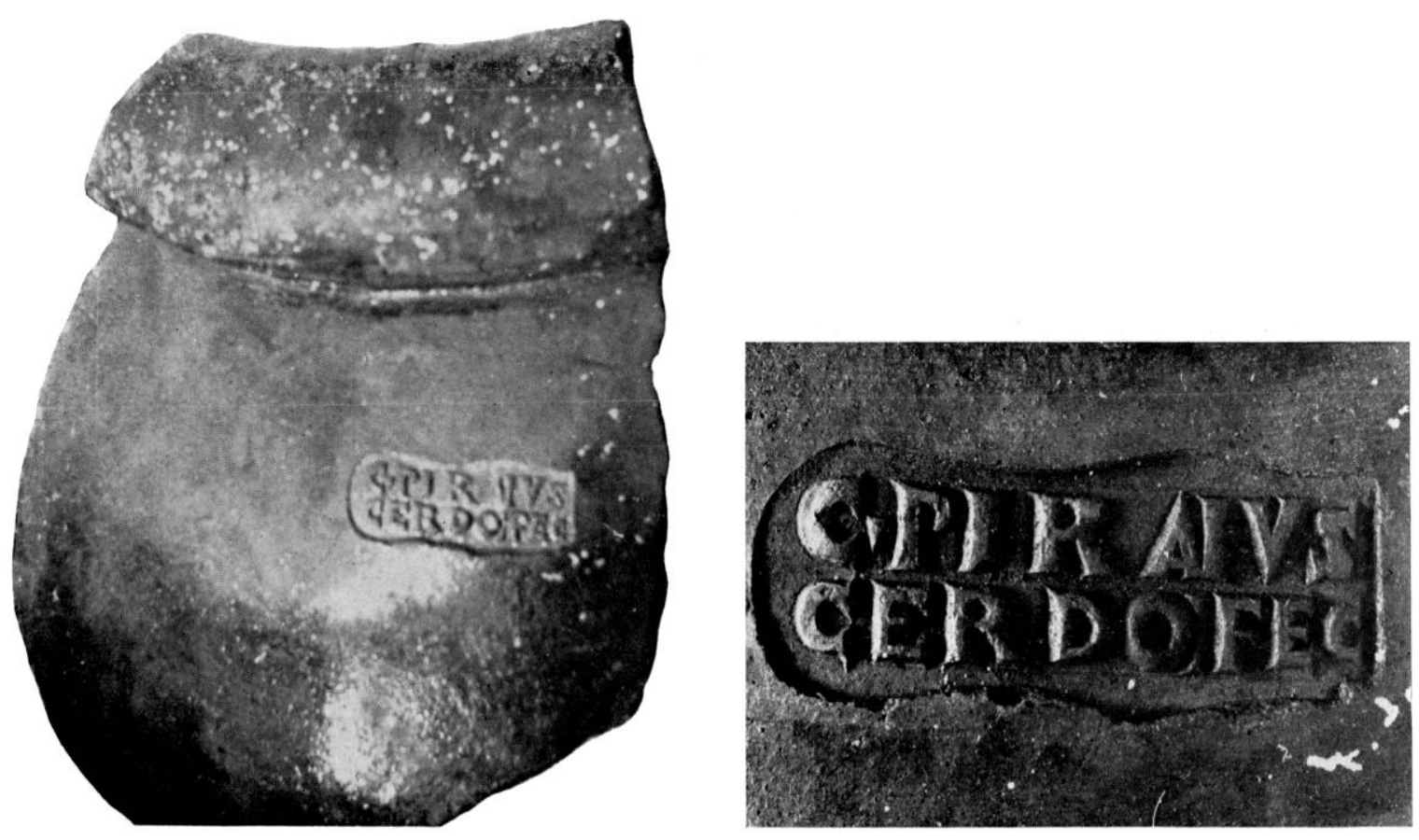

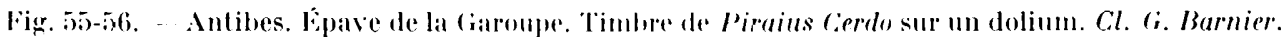


mème provenance aux amphores de ce type. dont certains exemplaires trourés à .llba Fucens ${ }^{68}$ portent un timbre grec (MI. (i. Barnier. L. Jehoux).

31. Villefranche. - A 300 metres du phare du Cap Ferrat. a l'entrée de la rade. a -25 metres, amphore isolée de type romano-punique lype ci de llaña; Almagro $23: 3$ : (musée de Cimiez). - Dans la rade, amphore massalicheroüde (II. Portelatine).

\section{Moxico}

32. Monaco. - La prospection du port de Monaco malleureusement bouleverse par des dragages a permis de : repêecher" des céramiques du yer s. ar. J.- C. : patère campanienne à hord horizontal incurvé sans palmelte (camp. A. forme Lamloglia 36), cols d'amphores gréco-italiques à panse curviligne of livere inclinéper. amphores italiques (Dressel IA et B).

L'étude du navire marchand, échoué à peu de profondeur dans le fond du port et menacé d'être recouvert par l'aménagrement de cette plage. montre l'intérêt de cette epare (1961). Lne section de la carene faite en 1958 sous la direction du didt Avilat ratlache celle-ci au type de vaisseau a membrures d'un seul tenant maintenues par une quille et une carlingue ; la carène a conservé son vaigrage et ses bordés. dont l'assemblage suit la tradition des carènes déjà connues. Le prélèvement d'un segment de la quille à la jointure de deux éléments montre le parfait assemblage de ceux-cion.

Le chargement comportait des amphores du nue siècle (1)ressel-Pelichet 30/47), de la céramique sigillée claire rougeâtre dénaturée par la vase (forme $\mathrm{A}$ tardif $=9$ ), fragment de lampe à que ue percée du mi siècle.

ln certain nombre de cols d'amphores portent des marques estampésest. CiglI, ATs, cercle entouré de points, ou incisées après cuisson IC:T. VIC, palme, dessin représentant un phare sur deux exemplaires" ${ }^{71}$. Il a été remonté également une matriere en bois dur (buis ?) circulaire (diam. 0.08) pour l'estampillage de houchons de chaux port ant rn relief entre deux palmes ti.A.F., et une monture de lanterne en bronze.

En face du Tir aux Pigeons, épave d'amphores de type gréeco-italique à panse curviligne et lère inclinée et meule en basalte complete.

A proximité du port de Fontvieille-Monaco. plusieurs jas d'ancre dont un aver sa pièce d'assemblage.

La recherche sur le haut iond rocheux de Saint-Vienlas. où avait été trouvée une panthère de bronze (Jusée de Saint-(rermain) a permis de recueillir trois amphores ovoüdes à huile (IDressel 9) et une corne de taureau ou de bélier en plomb (Iong. 0.31) analogue à celle d'Albenga ${ }^{72}$. Elle porte l'empreinte des nervures internes d'une corne réelle. dans laquelle aurait été coulé le plomb, destiné à donner de la rigidité a l'attribut. Cies corness

(68) Gallia, XIV-1956, p. 26, 1 ; Rev. El. ligures, 23, 1957, p. 256, fig. 8-10. Sur ce lype dit de Cos : V. (inack, Amphoras, fig. 57 et 60 .

(69) Type du Grand Congloné : L'epale..., p. 36 et pl. I I, 1 ; cf. Typologia, Rev. Et. ligures, :23, 1957, p. 25:3, figr. 33-7.

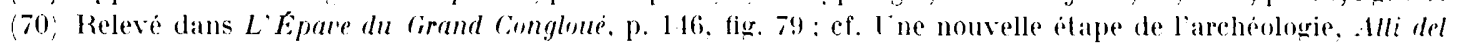
IIJe Congresso internaz. di Archeologia classica 1959!. I. p. 61.

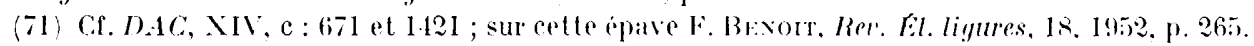

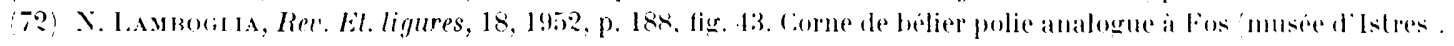




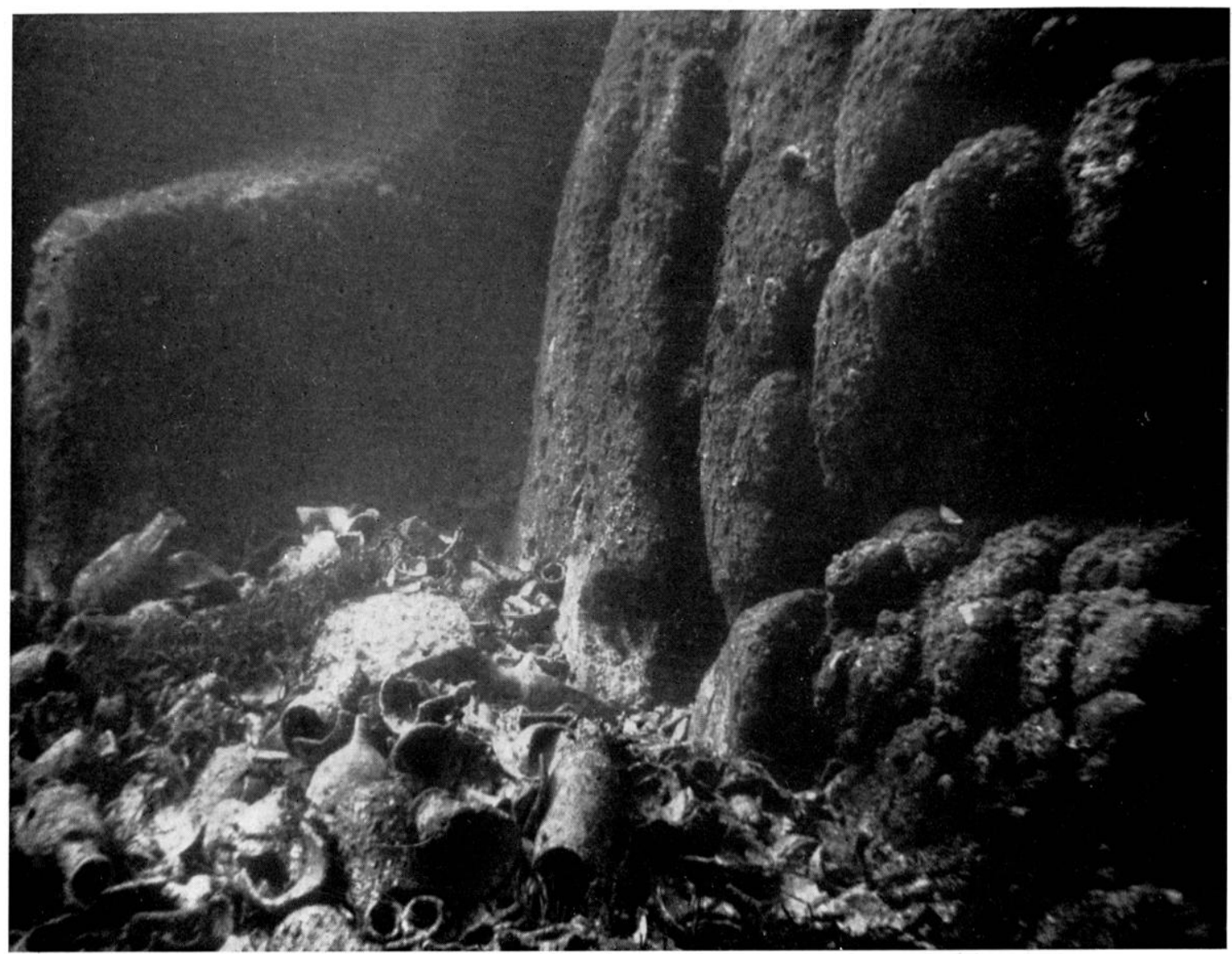

Fig. 57. Corse. le "cimetiere marin" des iles l.ailergi-tavallo an pied du fombant.

presentent une série de trous, les uns aveugles provenant du clouement de la corme a la masse de plomb, les autres de section rarré (clou de cuivere en place dans l'exemplaire de Monaco) traversant le plomb de part en part pour fixer la corne au bateau, selon l'hypothesse de .J. Boissy. les cornes qui ne paraissent pas avoir éte liées à un huerane, avaient une valeur apotropaïque, soit qu'elles aient servi à la décoration de l'aphustre (enseigne on laenia). soit qu'elles aient été fixées en proue, à la préereinte (Salle de la mer, Vlusée anthropologique de .lonaco).

\section{CORSE}

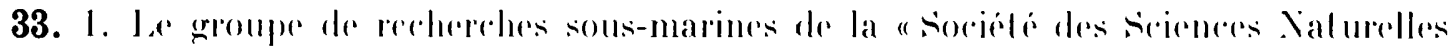
de la Corse n: 1)r J. Biaggri. Bastia) a éludié l'un des gisements le plus anciennement connu et pillér3 du détroil de Bonifario : le "cimetiere marin "silue au large du Cap siperone.

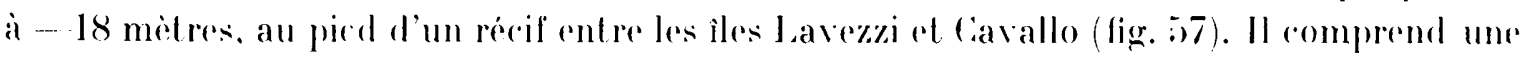
grande variéte d'amphores : amphores gréco-italiques a bourreled ol anses bifides

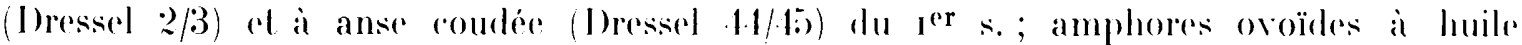
(Tressed 10). sphériques à huile ou à olives (I)ressel ?0) (lign. is ) et a saumure, à pied conique

(73) Singestre de la spezzia : Gallia, Nill I-1960, p. 56, 17. Amphores ramenies en corse en 1962. 


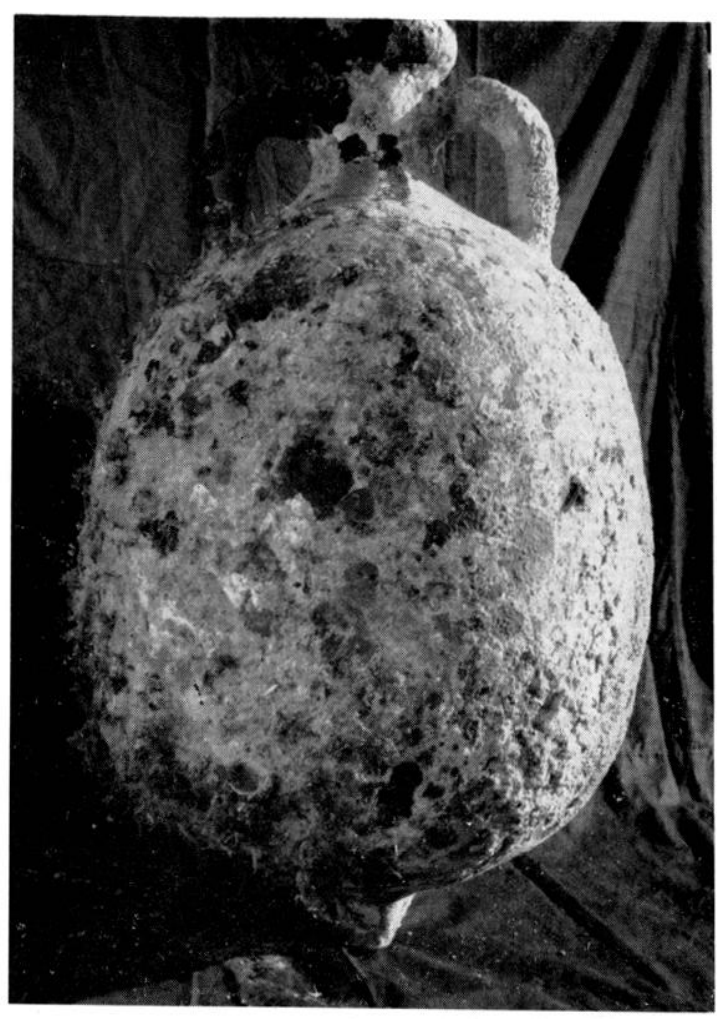

lïg. jx. - Corse. Cisement Iaverzi-calvallo. Amphore sphoricue à olives.

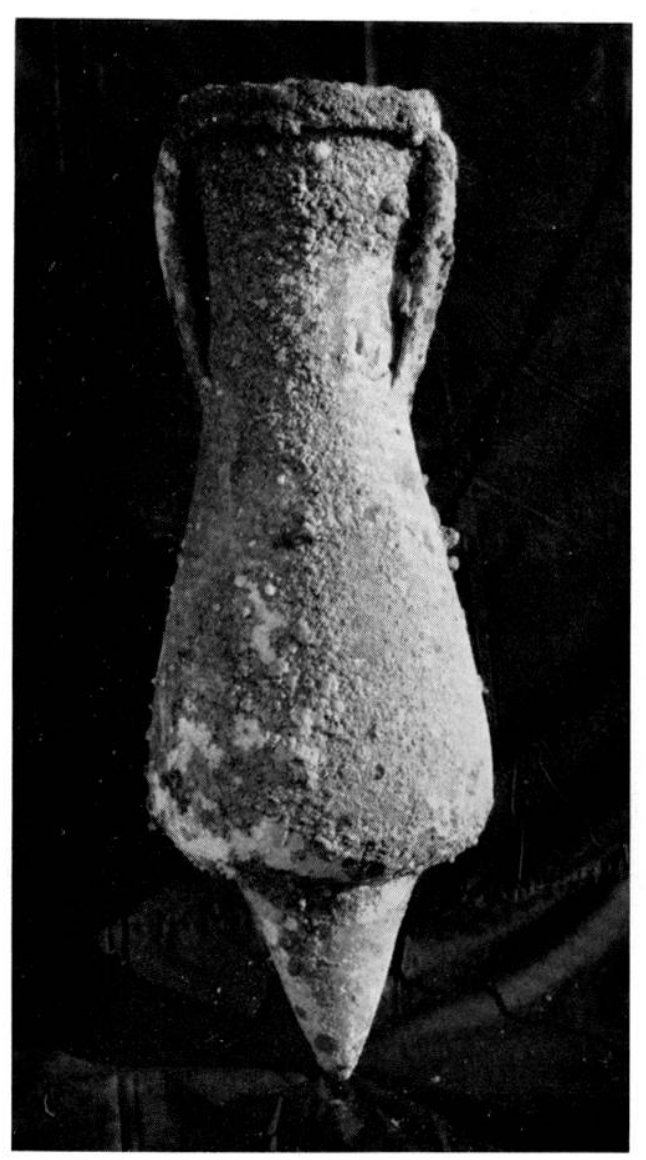

Figg. 59-60-61. Gisement Javerzi-Cavallo. Variantes de l'amphore à sanmure du lype d'Augst. (:I. I) Biaggi.
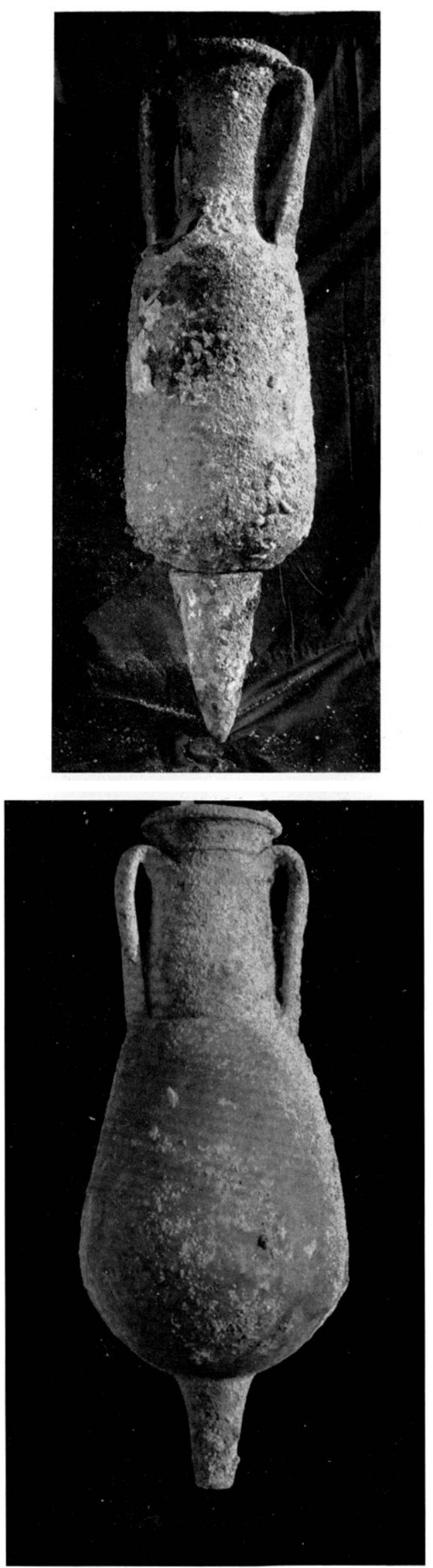
ot col évasé (fig. 59-61) (type d'Augst : I)ressel 6/14; Pelichet. 46), ces trois derniers Lypes originaires de Bétique; un grand nombre de bouchons de terre cuite a tenon de préhension.

C'est à la même provenance hispanique qu'appartiennent dix flans de cuivere en forme de disque plat (diam. 0.33, 34 et 38 ; ép. 0.06), d'un poids de 22 kil. 500 à 24 kil. analogues. a ceux de plus grande dimension (50) kilos) d'une autre épave reconnue à la balise du Prètre ${ }^{74}$. L'analỵse de .I. R. Maréchal a révélé une teneur en arsenic, argent et antimoine analogure a celle des lingots de cuivere de Planier 4, caractéristique des mines de la sierra Morena ${ }^{75}$. De la mème épare provient un lingot de plomb prismatique avee contremarque sur le côté, corrodée (long. 0,48 ; ép. 0,11 ; haut. 0.11 ; poids :2) kil. 200).

L'identification de celle épave permet de tracer l'itinéraire d'un vaisseau marehand entre les mines métalliques du sud de l'Espagne (Carthagène) et le port d'(ostie, par le: détroit de Bonifacio.

2. Ie Centre d'Etudes sous-marines de M. II. Chénevèe a continué la prospection du secteur des îles Lavezzi et Cavallo. Iess amphores appartenant à différents types ont été déposées à la citadelle de saint-Florent et au musée en formation de la Citadelle de Bonifacio.

3. A Cala Cirande (Bonifacio) M. V. Romanowsky a identifié par fond de $4 / 6$ mètres une épave d'amphores cylindriques du Bas Empire (I)ressel 26/27 ; Almagro 52:).

4. Ia Douane de Bonifacio a saisi 3 amphores à huile (1)ressel 10) et un lingot de plomb prismatique (long. 0.47) portant sur la tranche supérieure trois marques corrodées, comme les lingots de l'îlot Ciavetti ${ }^{76}$ et sur le còté une contremarque incisée J). VAL (erius) S E, avec ligature de VAL; provenane non précisée : vers les îles Lavezzi-ciavallo.

5. In crertain nombre de jas d'ancres en plomb ont été remontés; ; ces jas qui sont sans contexte d'épare ot ne peuvent ètre en conséquence datés, présentent cependant des variantes qui indiquent une (hronologie: jas de Centuri (près du Capo Bianco) à hoite an ovale arrondi. a armature de bois transversale, formant te tenon de fixation de la verge (disparu), à bras rectilinéaires (lonğ. 1,91) et jas de mème type du laap ciorse (banc de Sainte-Marie). dont le doublage de plomb est corrodé, avec grandes lettres ou signes en relief incomplets (long. 1.57), analogues au jas de Villefranche, ayant également une armature de bois7n et au jas étrusque d'Antibes, à boîte carrée, sans armature de bois ni tenon de la verge, qui est le plus ancien ${ }^{78}$; jas do saint-Florent, massif, à tenon de plomb, à bras anguleux, dont la face plane porte les traces de retassures de fonderie (long. 1,65) ; petit jas du Capo Bianco, au N.. de Cient uri, massif, a tenon de plomb (long. 0,46).

6. Pour mémoire, découverte ancienne d'un trésor de monnaies d'or (41 pièces) du III siède de notre ère sur les còtes de la ciorsere.

Frornand BexolT, Membre de l'Inslitul.

(74) Gallia, NV1-1958, 1. 39, 5.

(75) Supra, no 7 .

(76) Gallia, Xvill-1960, p. 55, fig. 95.

(7i) Gallia, NV1-1958, p. 38, fig. 49.

(78) Ibid., p. 30, fig .36.

(79) J. Larauhie, Bull. Soc. Nal. Antiq., 1959, p. 36. I.e mème auteur signale un autre trésor anterieur a 308 , trouvé sur les còtes de Sardaigne ou de Sicile. 